\title{
CO adsorption over Pd nanoparticles: a general framework for IR simulations on nanoparticles
}

\author{
Constantinos D. Zeinalipour-Yazdi ${ }^{\dagger, *}, *$, David J. Willock ${ }^{\dagger, *}$, Liam Thomas $^{\dagger}$, Karen Wilson ${ }^{\bar{\top}}$ and Adam F. Lee ${ }^{\bar{\top}, *}$ \\ ${ }^{\dagger}$ Cardiff Catalysis Institute, Cardiff University, Park Place, Cardiff CF10 3AT, UK \\ * Department of Chemistry, University College London, London, WC1H OAJ, UK \\ ${ }^{\bar{\top}}$ European Bioenergy Research Institute, Aston University, Birmingham, B4 7ET, UK
}

KEYWORDS: Palladium; Nanoparticles; Carbon monoxide; Density functional theory; Chemisorption; IR spectroscopy

\begin{abstract}
CO vibrational spectra over catalytic nanoparticles under high coverages/pressures are discussed from a DFT perspective. Hybrid B3LYP and PBE DFT calculations of CO chemisorbed over $\mathrm{Pd}_{4}$ and $\mathrm{Pd}_{13}$ nanoclusters, and a $1.1 \mathrm{~nm} \mathrm{Pd}_{38}$ nanoparticle, have been performed in order to simulate the corresponding coverage dependent infrared (IR) absorption spectra, and hence provide a quantitative foundation for the interpretation of experimental IR spectra of CO over Pd nanocatalysts. B3LYP simulated IR intensities are used to quantify site occupation numbers through comparison with experimental DRIFTS spectra, allowing an atomistic model of CO surface coverage to be created. DFT adsorption energetics for low CO coverage $(\theta \rightarrow 0)$ suggest the $\mathrm{CO}$ binding strength follows the order hollow $>$ bridge > linear, even for dispersion-corrected functionals for sub-nanometer Pd nanoclusters. For a $\mathrm{Pd}_{38}$ nanoparticle, hollow and bridge-bound are energetically similar (hollow $\approx$ bridge $>$ atop). It is well known that this ordering has not been found at the high coverages used experimentally, wherein atop CO has a much higher population than observed over Pd(111), confirmed by our DRIFTS spectra for Pd nanoparticles supported on a KIT-6 silica, and hence site populations were calculated through a comparison of DFT and spectroscopic data. At high CO coverage $(\theta=1)$, all three adsorbed CO species co-exist on $\mathrm{Pd}_{38}$, and their interdiffusion is thermally feasible at STP. Under such high surface coverages, DFT predicts that bridge-bound $\mathrm{CO}$ chains are thermodynamically stable and isoenergetic to an entirely hollow bound $\mathrm{Pd} / \mathrm{CO}$ system. The $\mathrm{Pd}_{38}$ nanoparticle undergoes a linear (3.5\%), isotropic expansion with increasing CO coverage, accompanied by 63 and $30 \mathrm{~cm}^{-1}$ blueshifts of hollow and linear bound CO respectively.
\end{abstract}

\section{Introduction}

$\mathrm{CO}$ adsorption and activation over platinum group metals (PGMs, i.e. Pt, Ir, Ru, Rh, and Pd) [1] are key steps in some of the world's most important catalytic processes [2,3]. Early surface science studies by Ertl and co-workers shed valuable light on $\mathrm{CO}$ adsorption/oxidation (i.e. $\mathrm{CO}+1 / 2 \mathrm{O}_{2} \rightarrow \mathrm{CO}_{2}$ ) on palladium surfaces, evidencing a competitive LangmuirHinshelwood mechanism [4-8]. Nowadays, palladium is a key component of automotive emission control three-way catalysts (TWCs) for gasoline vehicles, facilitating low temperature oxidation [9]. Supported PGMs have also shown outstanding low temperature performance for the water-gas shift (WGS) reaction (i.e. $\mathrm{CO}+\mathrm{H}_{2} \mathrm{O} \rightarrow \mathrm{CO}_{2}+\mathrm{H}_{2}$ ) [10], the electrochemical oxidation of $\mathrm{CO}$ [11], and $\mathrm{CO}$ methanation in which $\mathrm{CO}$ coverage-dependent rate changes of 2-3 orders of magnitude have been recently observed [12]. These important processes place a heavy demand on the supply of these costly and scarce elements. To mitigate the cost and improve the sustainability of PGM catalysts, academic and industrial researchers seek more efficient catalyst designs, such as supported nanoparticles (NPs), which offer very high surface area to volume ratios for the active metal component, or alloying with a non-noble metal to minimise the precious metal content and tailor its electronic properties [13]. A strong NP/support interaction is also desirable to hinder particle sintering and attendant loss of active surface area.

In addition to its roles in pollution control and chemical synthesis, $\mathrm{CO}$ is also widely employed in heterogeneous catalysis as a strongly-interacting probe molecule for evaluating the dispersion and morphology of PGM nanoparticles via thermal desorption and/or vibrational spectroscopies $[14,15]$. However, the correct interpretation of resulting experimental spectra is critically dependent upon a quantitative understanding of factors influencing the observed $\mathrm{CO}$ stretching frequency, which to date has only been derived via surface science experiments over well-defined single crystal surfaces. For nanoparticulate catalysts such CO stretching frequencies are anticipated to be sensitive to NP size, the exposed facets, support interactions, and coverage dependent (substrate-mediated or direct) lateral interactions between co-adsorbed CO molecules: these effects are extremely difficult to probe independently through experiment. Density functional theory (DFT) calculations offer a powerful methodology by which to estimate the energetic, structural and spectroscopic properties of CO over free and supported transition and noble metal clusters [16-21] and oxides [22]. We have therefore undertaken the first systematic DFT level calculations, and associated IR spectral simulations, of CO over a family of related, isolated Pd clusters seeking to quantify the influence of particle size and CO coverage based only on the intrinsic properties of the metal NPs. The resulting calculations offer valuable insight into the fundamental processes that occur during $\mathrm{CO}$ adsorption over metal NPs under 'real world' conditions of high coverage and/or pressure [16].

CO adsorption on Pd surfaces and NPs has been investigated by both experiment and theory [4, 23-26]. Early photoelectron diffraction experiments showed that at low coverage $(\theta=0.1-0.5)$ CO preferentially adsorbs at three-fold 
hollow sites on $\operatorname{Pd}(111)$ [27]. At higher coverage $(\theta=0.6-0.7)$ the preference switches to bridge sites, with atop species only appearing at very high surface densities $(\theta=0.75)$ [28]. Goodman and co-workers examined CO adsorption over $\operatorname{Pd}(111)$ and $\operatorname{Pd}(100)$ [29] single crystals at low and high coverage via temperature programmed desorption (TPD) and surface IR spectroscopy (RAIRS), uncovering a correlation between the activation energies for desorption and corresponding rates of $\mathrm{CO}$ oxidation. For Pd NPs, Wolter et al performed a systematic study of $\mathrm{CO}$ over $\mathrm{Pd} / \mathrm{Al}_{2} \mathrm{O}_{3} / \mathrm{NiAl}(100)$. A strong atop signal was observed by RAIRS for small NPs (10-50 atoms), in addition to a contribution from bridge sites which becomes more important for larger particles. Upon heating, atop CO desorbed first leaving only bridge-bound molecules $>335 \mathrm{~K}$ for 300 atom NPs. Dropsch and Baerns also studied CO adsorption on oxide supported Pd NPs by microcalorimetry and TPD [30], concluding that bridge-bound $\mathrm{CO}$ dominated at low coverages $(\theta<0.4)$, whereas three distinct $\mathrm{CO}$ species were observed at higher coverage. The size-dependence of CO adsorption on Pd NPs (120-4900 Pd atoms) supported over $\mathrm{Fe}_{3} \mathrm{O}_{4} / \mathrm{Pt}(111)$ was also explored by single-crystal microcalorimetry [31, 32]; a 20-40 $\mathrm{kJ}^{-\mathrm{mol}^{-1}}$ decrease in adsorption energy was noted with $\mathrm{CO}$ coverage, similar to that predicted by DFT calculations for a $\mathrm{Rh}_{4}$ nanocluster [16].

$\mathrm{CO}$ adsorption energetics have been extensively investigated by DFT over various transition and noble metal surfaces [33, $34]$ and clusters [17, 35]. In particular, it has been found that the site preference for CO adsorption on $\operatorname{Pt}(111)$ is incorrectly predicted by DFT methods, with predictions favouring high co-ordination $\mathrm{CO}$ adsorption sites over low co-ordination sites [34]. For Pd(111), three fold hollow sites are also calculated to provide the lowest adsorption energy for single CO molecules [36, 37] although this is in agreement with STM, LEED [38] and SFG [25, 39] studies. Rösch and coworkers recently calculated the size-dependent adsorption energy of CO on 13-116 atom Pd NPs [40, 41] for various low coverage structures, identifying 50-100 atom clusters as the optimum to minimise $\mathrm{CO}$ adsorption, although this finding may have been influenced by the choice of the simple LDA functional, particularly in the light of recent microcalorimetric data from Schauermann and co-workers which evidenced a decrease in adsorption energy with NP size [31].

Here we investigate the impact of Pd NP size and CO coverage on the energetics of CO adsorption, with a view to establishing a general framework within DFT for accurately simulating the IR vibrational spectra of CO over palladium nanoparticulate catalysts. Such a theoretical basis will aid the interpretation of experimental IR spectra in respect of the nature, number density, and adsorption strength of different $\mathrm{CO}$ species bound to practical catalysts, and hence enhance the utility of IR spectroscopies (DRIFTS, ATR-IR and RAIRS) routinely employed to determine the morphology and electronic structure of practical PGM catalysts [18, 42]. We find that structural (e.g. average Pd-Pd and C-O bond lengths), energetic (e.g. $\mathrm{CO}$ adsorption enthalpy) and spectroscopic properties (e.g. C-O stretching frequency and dipole) of the $\mathrm{CO} / \mathrm{Pd}_{\mathrm{n}} \mathrm{system}$ evolve strongly with particle size and $\mathrm{CO}$ coverage. The coverage dependent heat of $\mathrm{CO}$ adsorption on $\mathrm{Pd}_{38} \mathrm{NP}$ and associated relative stability of different adsorption sites is also rationalised.

\section{COMPUTATIONAL METHODS}

Restricted and unrestricted DFT calculations were used, as implemented in Gaussian 09 [43], with the commonly used B3 exchange functional [44] combined with the LYP non-local correlation functional [45] (B3LYP). We also briefly tested other exchange-correlation (XC) functionals: M06-2X [46], TPSSh [47], LC-wPBE [48], PBE [49], B3PW91 [44, 50] (see supporting information, S-Fig. 1) which yielded the same relative total energy order for $\operatorname{Pd}_{4}(3,1)$ at various spin multiplicities (s.m.). We adopted a computational strategy whereby the structures of $\operatorname{Pd}_{4}(3,1)$ and $\operatorname{Pd}_{13}(3,7,3)$ clusters were first fully optimized at a UB3LYP/CEP-121G(Pd), aug-cc-pVTZ(C,O) level of theory, in order to identify the possible adsorption configurations (e.g. linear, bridge and hollow). This level of theory was found sufficient among basis sets/ECP of varying size, LanL2mb [51, 52], LanL2dz [52, 53], CEP-121G [54, 55], aug-cc-pVTZ [56-60] and QZVP [61, 62], to yield converged adsorption energies $\left(\Delta \mathrm{E}_{\text {ads }}\right)$ to within a few $\mathrm{kJ} \cdot \mathrm{mol}^{-1}$ of the basis set superposition error (BSSE) corrected adsorption energies $\left(\Delta \mathrm{E}_{\mathrm{BSSE}}\right)$ obtained by the counterpoise method of Boys and Bernardi [63]. In Fig. 1 we show that the basis set/ECP CEP-121G(Pd),aug-cc-pVTZ(C,O) yields quantitatively similar results to the computationally intensive QZVP basis set that contains twice as many basis functions. Full optimization is critical [64] since strong adsorption-induced structural changes to the transition metal cluster were observed, especially for the Pd nanoclusters (i.e. $\mathrm{Pd}_{4,13}$ ). Linear dependencies of the basis functions were removed by using the spherical version (5d and 7f) of these basis sets. The SCF convergence criteria for the root mean square (rms) density matrix and the total energy were respectively set to $10^{-8} \mathrm{e}^{\mathrm{bohr}} \mathrm{bon}^{-3}$ and $10^{-6}$ Hartree. 


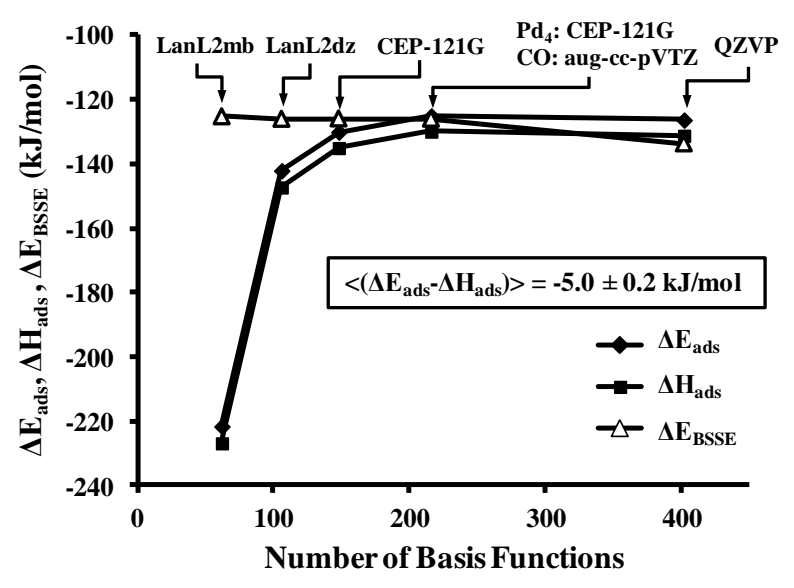

Figure 1. Adsorption energy, enthalphy and BSSE-corrected energy as a function of the number of basis functions for Pd ${ }_{4}$ 1CO. Open shell calculations were also examined for spin contamination, which was found to be negligible.

Calculations for the larger $\mathrm{Pd}_{38}$ NP were obtained via spin-polarized $\Gamma$ point [65] calculations using VASP 5.3 [66, 67]. Exchange and correlation effects were considered within the generalized gradient approximation (GGA) using the PerdewBurke-Ernzerhof [68] (PBE) XC functional, with the projector augmented-wave (PAW) method [69, 70] used to represent core states ( $1 \mathrm{~s}$ for $\mathrm{C}$ and $\mathrm{O}$, and $1 \mathrm{~s}$ to $4 \mathrm{p}$ for $\mathrm{Pd}$ ). The cut-off energy for plane-wave expansion was set to 500 eV. Nanoparticle/adsorbate models were centred within a $30 \AA$ cubic box to ensure a sufficient vacuum gap around the cluster/adsorbate system. Geometry optimizations were performed with a residual force threshold of $0.015 \mathrm{eV} . \AA^{-1}$ using the conjugate-gradient algorithm. Convergence criteria for the electronic relaxation during optimization (frequency) calculations were based on the change of energy between SCF cycles with a threshold of $10^{-4} \mathrm{eV}\left(10^{-7} \mathrm{eV}\right)$. The initial charge density was obtained by superposition of atomic charges, and the projection operators were evaluated in reciprocal space.

We note that, for metallic systems, the B3LYP functional is not regularly used due to its failure to recover the homogeneous electron gas solution for itinerant electron states in bulk metals [71]. For metal complexes the functional is quite widely used and a combined B3LYP/CCSD(T) study has appeared for cationic group 10 and group 11 carbonyl complexes [72]. The nanoclusters considered here are intermediate in size. We use the B3LYP functional only for its reliability in vibrational analysis including intensity estimates for the IR modes of CO on the smaller clusters. The total adsorption energy per $\mathrm{CO}$ molecule $\left(\Delta \mathrm{E}_{\mathrm{ads}, \mathrm{CO}}\right)$ was calculated using,

$$
\Delta \mathrm{E}_{\mathrm{ads}, \mathrm{CO}}=\left(\mathrm{E}_{\mathrm{Pdm}(\mathrm{CO}) \mathrm{n}}-\mathrm{E}_{\mathrm{Pdm}}-\mathrm{n}_{\mathrm{CO}} \cdot \mathrm{E}_{\mathrm{CO}}\right) / \mathrm{n}_{\mathrm{CO}}
$$

where $E_{i}$ is the total energy of fully optimized species $i$ and $n_{C O}$ the number of adsorbed CO molecules. Note that this definition means that negative adsorption energies are favourable compared to gas phase $\mathrm{CO}$ and a free nanoparticle. The surface coverage of $\mathrm{CO}$ has been defined based on the following equation

$$
\theta_{\mathrm{CO}}=\mathrm{n}_{\mathrm{CO}} / \mathrm{n}_{\mathrm{Pd} \text {,surf }}
$$

where $n_{P d, s u r f}$ is the number of surface Pd atoms of the NP. The vibrational frequencies were explicitly calculated by diagonalizing the Hessian matrix using the finite-difference (FD) method. Additional calculations using the densityfunctional-perturbation-theory (DFPT) method within VASP were used to ensure that agreement within $2 \mathrm{~cm}^{-1} \mathrm{could}^{\mathrm{be}}$ obtained with this computational protocol. The relative intensities of linear-CO (1CO), bridge (bCO) and three-fold (3f) hollow (hCO) species were calibrated against the results for tetrahedral $\left(\mathrm{T}_{\mathrm{d}}\right) \mathrm{Pd}_{4}(3,1)$ and cubooctahedral $\left(\mathrm{O}_{\mathrm{h}}\right) \mathrm{Pd}_{13}(3,7,3)$. Infrared spectra were simulated by fitting a Lorentzian function with a FWHM $=15 \mathrm{~cm}^{-1}$, centred at each stretching frequency calculated from the FD method.

\section{RESULTS AND DISCUSSION}

3.1 Effect of NP size on CO adsorption. Previous computational [41, 64] and microcalorimetric [32] studies of CO adsorption on Pd NPs have suggested a strong cluster size-dependence. At low coverages, CO adsorption energies can vary by almost $100 \mathrm{~kJ} \mathrm{~mol}^{-1}$ (falling from $-202 \mathrm{~kJ} \mathrm{~mol}^{-1}$ for $\mathrm{Pd}_{13}$ to $-109 \mathrm{~kJ} \mathrm{~mol}^{-1}$ for $\mathrm{Pd}_{25}$ ), resulting in a critical cluster size $(50$ 100 atoms) wherein $\mathrm{CO}$ adsorption is weakest [41]. Another microcalorimetry study showed that initial heats of adsorption that fall linearly with particle size from the $\mathrm{Pd}(111)$ surface value of $149 \pm 3 \mathrm{~kJ} \mathrm{~mol}^{-1}$ down to $106 \pm 1 \mathrm{~kJ}^{\mathrm{mol}}{ }^{-1}$ for particles of $2 \mathrm{~nm}$ dimension [31]. Adsorption microcalorimetry offers precise adsorption heats [73, 74], but no direct insight, into CO 
bonding modes. Atomistic simulations herein, provide adsorption energies of $\mathrm{CO}$ species according to their structural identification (i.e. $1 \mathrm{CO}, \mathrm{bCO}$ or hCO), however it is clear from the introductory discussion of site preference that this is likely to give insufficient accuracy to allow relative abundances $\left(\mathrm{n}_{\mathrm{lCO}}, \mathrm{n}_{\mathrm{bCO}}, \mathrm{n}_{\mathrm{hCO}}\right)$ to be determined. However, DFT calculations can be used to interpret IR spectroscopic signatures of adsorbed CO species by obtaining the IR intensity factors as a function of $\mathrm{CO}$ position, and then using experimental data to interpret the site populations. IR intensity calculations are not currently available in VASP for these systems, and are most accurate using a hybrid functional method for which the computational expense increases rapidly with system size. Accordingly, we have performed calculations using small reference systems $\left(\mathrm{Pd}_{4}\right.$ and $\mathrm{Pd}_{13}$ ), and extrapolated the results to the larger $\mathrm{Pd}_{38}$ cluster size. The choice of hybrid B3LYP functional for the calculation of IR oscillator frequencies was based on its earlier success in the spectral band assignment of diffuse reflectance infrared Fourier-Transform (DRIFT) spectra obtained for $\mathrm{CO}$ chemisorption over a highly dispersed $\mathrm{Rh} / \gamma-\mathrm{Al}_{2} \mathrm{O}_{3}$ catalyst [18]. Due to computational cost, this method is limited to the smaller cluster sizes with single adsorbates. Therefore we additionally employed the more commonly used PBE functional for the largest cluster size, and to examine coverage effects.

Here, we briefly examine the dependence of $\mathrm{CO}$ adsorption energy on Pd cluster size, before considering the effect of $\mathrm{CO}$ surface coverage. The energetics of $\mathrm{CO}$ chemisorption were studied for three high symmetry Pd particles: tetrahedral $\mathrm{Pd}_{4}(3,1)(0.4 \mathrm{~nm})$, cubooctahedral $\operatorname{Pd}_{13}(3,7,3)(0.8 \mathrm{~nm})$ and cubooctahedral $\operatorname{Pd}_{38}\left(\mathrm{O}_{\mathrm{h}}\right)(1.1 \mathrm{~nm})$. Three distinct configurations were identified and are presented in Fig. 2: linear $(\mathrm{lCO})$, bridge $(\mathrm{bCO})$ and hollow $(\mathrm{hCO})$ bound molecules, which resemble the stable adsorption configurations found over $\mathrm{Rh}_{4}(3,1)[10,17]$. Additionally, di-carbonyl (di-CO) and tri-carbonyl species (tri-CO) were stable on $\mathrm{Pd}_{4}$ but could not be identified on $\operatorname{Pd}_{38}\left(\mathrm{O}_{\mathrm{h}}\right)$ and hence were not further considered. Calculated adsorption energies of $\mathrm{CO}$ at a low coverage $(\theta \rightarrow 0)$ are given in Table 1. For all adsorption sites we observe a strong particle size-dependence in good agreement with earlier theoretical studies [32, 41, 64]: on $\mathrm{Pd}_{4} \Delta \mathrm{E}_{\text {ads }}=-130$ to $-257 \mathrm{~kJ} . \mathrm{mol}^{-1}$; on $\mathrm{Pd}_{13} \Delta \mathrm{E}_{\mathrm{ads}}=-167$ to $-223 \mathrm{~kJ} \cdot \mathrm{mol}^{-1}$; and for $\mathrm{Pd}_{38} \Delta \mathrm{E}_{\text {ads }}=-161$ to $-196 \mathrm{~kJ} \cdot \mathrm{mol}^{-1}$. Interestingly, this cluster size-dependence of $\mathrm{CO}$ adsorption energy was dependent on the adsorption configuration. For hollow and bridge-bound $\mathrm{CO}, \Delta \mathrm{E}_{\text {ads, }}$ co indicates weaker binding with increasing NP size $(0.4 \mathrm{~nm} \rightarrow 1.1 \mathrm{~nm})$, whereas linear bound CO becomes more strongly bound. The calculated sensitivity of CO adsorption energy to NP size scales roughly with the coordination number (i.e. number of $\mathrm{Pd}-\mathrm{C}$ bonds), such that hCO $>\mathrm{bCO}>1 \mathrm{CO}$.

According to these results, the experimentally observed trend should then depend on the site occupancies for the three positions which may be influenced by sample pre-treatment. Campbell and co-workers [31] suggested that the experimentally observed weakening of adsorption could result from a Van der Waals dispersion effect, which would be expected to reduce with particle size. We have used the PBE-D2 method to test if dispersion energy is a significant factor and the results are presented in Table S1. The dispersion contribution to adsorption energies was small, and does not affect the observed trend with cluster size. The D2 correction is an atom-atom interaction model which does not include dispersion interactions with the delocalised electrons of a metal. Nevertheless, these calculations indicate that dispersion effects for CO on metals at low coverage are likely negligible. We speculate that the trend in adsorption energy with particle size reported by Campbell may be an indication that the hollow and bridge site populations were high in their experiments.

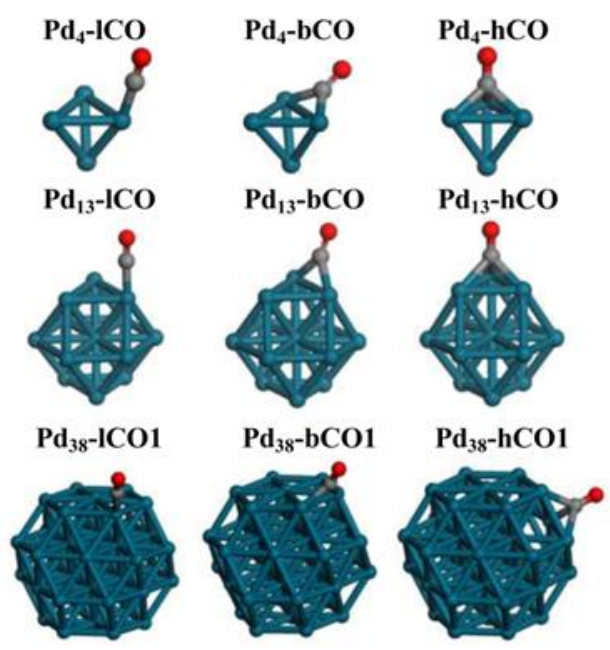

Figure 2. Structures for linear, bridge and three-fold (3f) hollow bound $\mathrm{CO}$ on $\mathrm{Pd}_{4}(3,1), \mathrm{Pd}_{13}(3,7,3)$ and $\mathrm{Pd}_{38}\left(\mathrm{O}_{\mathrm{h}}\right)$, respectively. 
Table 1. Vibrational stretching frequency, intensity, bond length and adsorption energy of $\mathrm{CO}(\mathrm{g})$, and $\mathrm{CO}$ on $\mathrm{Pd}_{4}$ and $\mathrm{Pd} \mathrm{d}_{13}(\mathrm{~B} 3 \mathrm{LYP} / \mathrm{CEP}-$ $121 \mathrm{G}(\mathrm{Pd})$,aug-cc-pVTZ(C,O)) and $\mathrm{Pd}_{38}$ (PBE, planewaves, $\mathrm{E}_{\mathrm{cut}}=500 \mathrm{eV}, 30 \AA$ cubic box), NPs respectively. The optimised structures of $\mathrm{Pd}_{4}, \mathrm{Pd}_{13}$ and $\mathrm{Pd}_{38}$ had a s.m. of 3, 7 and 9, respectively (S-Fig. 1).

\begin{tabular}{|c|c|c|c|c|c|c|}
\hline label & p.g. ${ }^{a}$ & S.m. ${ }^{b}$ & $\begin{array}{l}\mathbf{v}^{b} \mathrm{C}-\mathrm{o} \\
\left(\mathrm{cm}^{-1}\right)\end{array}$ & $\begin{array}{c}\mathbf{I}^{b} \mathrm{C}-\mathrm{O} \\
\left(10^{6} \mathrm{~m} \mathrm{~mol}^{-1}\right)\end{array}$ & $\begin{array}{c}\mathbf{r}^{b} \mathrm{C}-\mathrm{o} \\
(\AA)\end{array}$ & $\begin{array}{c}\Delta \mathbf{E}_{a d s} \\
\left(\mathrm{~kJ} \cdot \mathrm{mol}^{-1}\right)\end{array}$ \\
\hline $\mathrm{Pd}_{4}-\mathrm{ICO}$ & $\mathrm{C}_{1}$ & 3 & 2102 & 1125 & 1.139 & -130 \\
\hline $\mathrm{Pd}_{4}-\mathrm{bCO}$ & $\mathrm{C}_{2 \mathrm{v}}$ & 1 & 1879 & 587 & 1.171 & -208 \\
\hline $\mathrm{Pd}_{4}-\mathrm{hCO}$ & $\mathrm{C}_{3 \mathrm{v}}$ & 1 & 1768 & 475 & 1.187 & -257 \\
\hline $\operatorname{Pd}_{13}-\mathrm{ICO}$ & $\mathrm{C}_{\mathrm{s}}$ & 3 & 2088 & 1396 & 1.142 & -149 \\
\hline $\mathbf{P d}_{13}-\mathrm{bCO}$ & $\mathrm{C}_{\mathrm{s}}$ & 3 & 1931 & 955 & 1.161 & -198 \\
\hline $\mathrm{Pd}_{13}-\mathrm{hCO}$ & $\mathrm{C}_{3 \mathrm{v}}$ & 3 & 1827 & 815 & 1.175 & -200 \\
\hline Pd $_{38-1 C O 1}$ & $\mathrm{C}_{\mathrm{s}}$ & $9^{c}$ & 2058 & - & 1.150 & -161 \\
\hline Pd38-bCO1 & $\mathrm{C}_{\mathrm{s}}$ & $9^{c}$ & 1886 & - & 1.171 & -189 \\
\hline $\mathrm{Pd}_{38}-\mathrm{hCO} 1$ & $\mathrm{C}_{\mathrm{s}}$ & $9^{c}$ & 1786 & - & 1.185 & -196 \\
\hline $\mathrm{CO}(\mathrm{g})$ & $\mathrm{D}_{\infty \mathrm{h}}$ & 1 & 2131 & - & 1.133 & - \\
\hline
\end{tabular}

In Table 1, the stretching frequency $\left(v_{\mathrm{C}-\mathrm{O}}\right)$, IR intensity $\left(\mathrm{I}_{\mathrm{C}-\mathrm{O}}\right)$, bondlength $\left(\mathrm{r}_{\mathrm{C}-\mathrm{O}}\right)$ are also presented for the various configurations. Data for $\mathrm{Pd}_{4}$ and $\mathrm{Pd}_{13}$ are at the B3LYP level with a localized basis set so that calculated IR intensities can be included. We note that a linear adsorption mode results in a larger transition dipole moment than either hollow or bridge sites. For the $\mathrm{Pd}_{4}$ cluster, a singlet state was energetically favourable for the bridge and hollow adsorption modes, but for Pd4-ICO and the bare $\mathrm{Pd}_{4}$ cluster the triplet state is lower in energy, in agreement with an earlier study using B3LYP/LanL2dz [75] and detailed MCSCF studies of the low lying states of $\mathrm{Pd}_{4}$ [76]. For $\mathrm{Pd}_{13}$, we find the triplet state to be the lowest lying for all geometries, and for $\mathrm{Pd}_{38}$ a s.m. of 9 is found. This is consistent with the increased number and decreased energetic spacing of the metal electronic states as the cluster size is increased.

A linear correlation between CO bondlength and vibrational frequency was observed for all cluster sizes (Fig. 3a). For any adsorbed state, $\mathrm{r}_{\mathrm{C}-\mathrm{O}}$ was longer and the stretching frequency lower than in the gas phase, evidencing adsorption-induced weakening of the $\mathrm{CO}$ bond in accordance with the Blyholder model [77]. This trend also seems insensitive to the choice of functional, since B3LYP and PBE data follow the same trendline. Similar correlations have been reported for $\mathrm{Rh}_{4}(3,1)$ clusters using smaller atom-centred basis sets (i.e. LanL2dz) [18], and a similar decrease in vico observed via Infrared multiple photon dissociation (IR-MPD) spectroscopy for neutral $\mathrm{Pd}_{\mathrm{n}} \mathrm{CO}$ clusters where $\mathrm{n}=6,7,8$ and 9 [78]. It is evident from Fig. 3b that the $\mathrm{CO}$ bond weakens $\left(v_{\mathrm{C}-\mathrm{O}}\right)$ as the metal-carbonyl bond strength $\left(\Delta \mathrm{E}_{\text {ads }}\right)$, increases, again consistent with the Blyholder model. The IR intensities of various adsorbed configurations roughly scaled in the same fashion for $1 \mathrm{CO}, \mathrm{bCO}$ and hCO species on $\operatorname{Pd}_{4}(3,1)$ and $\mathrm{Pd}_{13}\left(\mathrm{O}_{\mathrm{h}}\right)$, with $\mathrm{lCO}: \mathrm{bCO}: \mathrm{hCO}=1.00: 0.68: 0.58$ (Fig. 4). This intensity ratio was therefore employed to estimate relative band intensities during the IR simulations described later. In summary, the vibrational frequencies $\left(v_{\mathrm{C}-\mathrm{O}}\right)$ and intensities $\left(\mathrm{I}_{\mathrm{C}-\mathrm{O}}\right)$ of adsorbed $\mathrm{CO}$ are inversely proportional to the exothermicity of adsorption. 

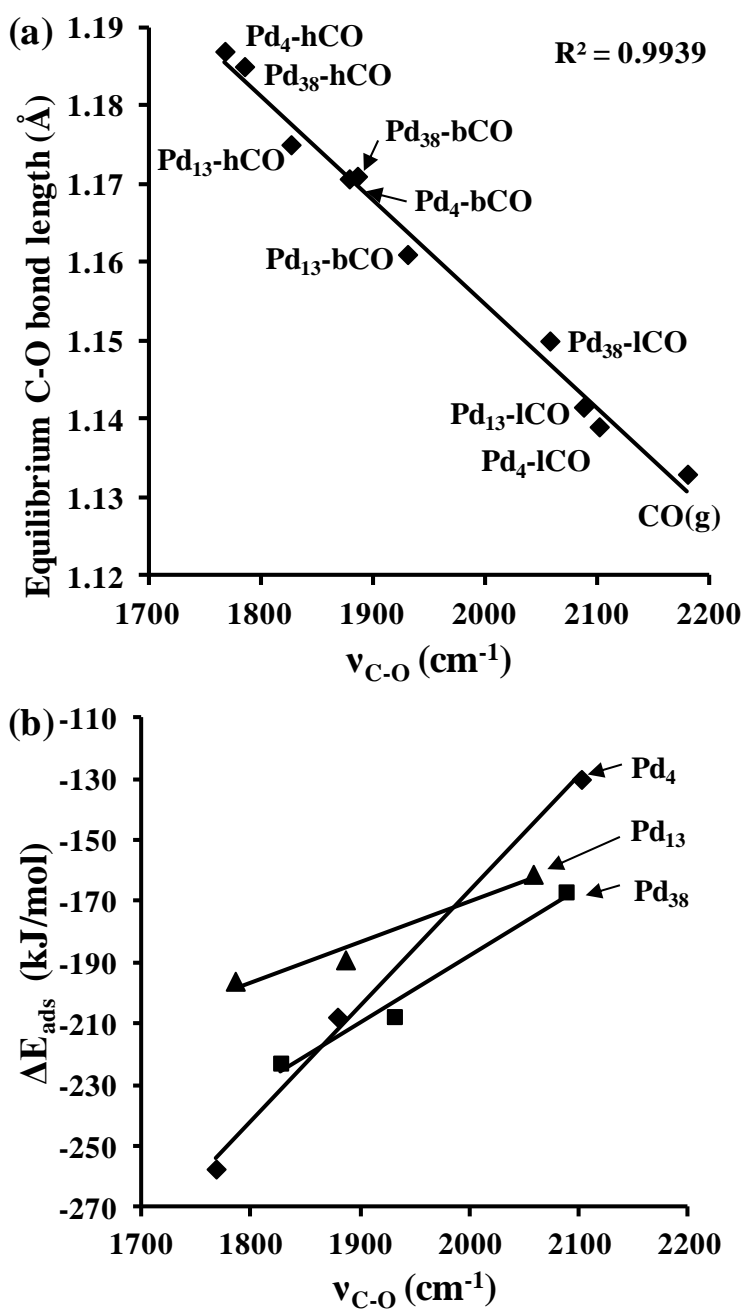

Figure 3. Correlation between (a) equilibrium $\mathrm{C}-\mathrm{O}$ bondlength and $\mathrm{CO}$ vibrational frequency, and (b) $\mathrm{CO}$ adsorption energy and $\mathrm{CO}$ vibrational frequency, for a CO molecule on $\mathrm{Pd}_{4}, \mathrm{Pd}_{13}\left(\mathrm{~B} 3 \mathrm{LYP} / \mathrm{CEP}-121 \mathrm{G}(\mathrm{Pd})\right.$, aug-cc-pVTZ(C,O)) and Pd $38\left(\mathrm{PBE}\right.$, planewaves, $\mathrm{E}_{\text {cut }}=500$ $\mathrm{eV}, 30 \AA$ cubic box) NPs.

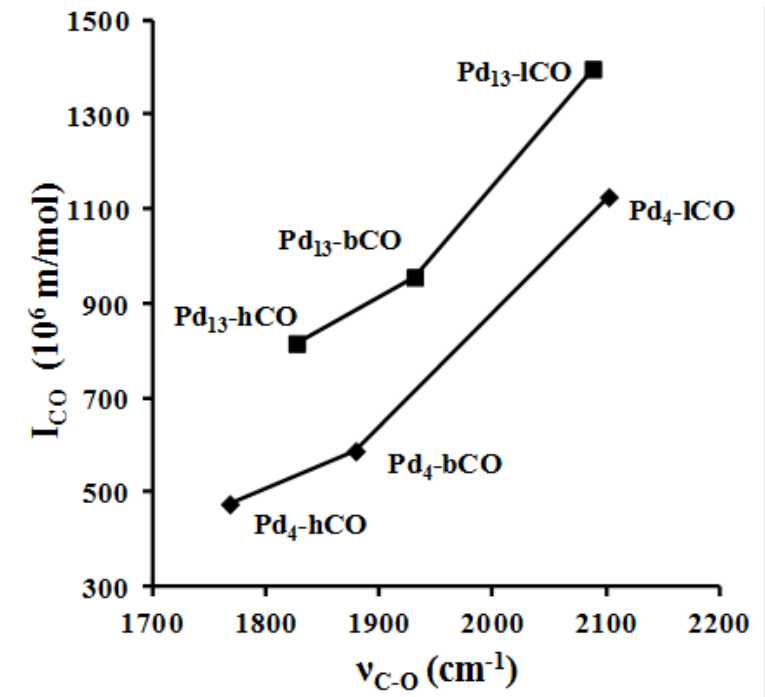

Figure 4. Correlation between the IR absorption intensity and CO vibrational frequency (B3LYP/CEP-121G(Pd),aug-cc-pVTZ(C,O)) for a $\mathrm{CO}$ molecule on $\mathrm{Pd}_{4}$ and $\mathrm{Pd}_{13} \mathrm{NPs}$. 
3.2. Low coverage CO adsorption on Pd38. In order to further explore the adsorption energetics of $\mathrm{CO}$ as $\theta_{\mathrm{CO}} \rightarrow 0$, additional calculations were undertaken for $\mathrm{CO}$ placed at every symmetry unique linear, bridge and hollow position on the cubooctahedral $\mathrm{Pd}_{38} \mathrm{NP}$ (Fig. 5), using the PBE functional. Full optimisation of the NP/adsorbate system showed that certain adsorbed configurations were unstable (e.g. bCO2, bCO4), with the $\mathrm{CO}$ molecule relaxing into adjacent adsorption sites.

As expected, for the PBE functional, we find that linearly adsorbed CO has a lower adsorption energy on $\mathrm{Pd}_{38}$ than bridge/hollow-bound $\mathrm{CO}$. The weakest bound $\mathrm{CO}$ species on $\mathrm{Pd}_{38}$ corresponded to linearly adsorbed $\mathrm{CO}$ at the vertex of the (100)-facet $(\mathbf{I C O 1}=\mathbf{I C O}(\mathbf{1 0 0 )})$, followed by linearly adsorbed CO on a (111)-facet $(\mathbf{I C O 2}=\mathbf{I C O}(\mathbf{1 1 1})$ ), with four-fold hollowbound $\mathbf{C O}$ at the (100)-site $\left(\mathbf{h C O 4}=\mathbf{h C O}_{(100)}\right)$ exhibiting a moderate adsorption strength. Bridge- $\left(\mathbf{b C O 1}=\mathbf{b C O}_{(100 / 111)}\right)$ and hollow-bound $\mathrm{CO}\left(\mathbf{h C O 1}=\mathbf{h C O}_{(\mathbf{1 0 0 / 1 1 1})}\right)$ at the edge of the $(100) /(111)$ facet were the next most stable configurations. The strongest adsorption site for $\mathrm{CO}$ at $\theta_{\mathrm{CO}} \rightarrow 0$ was the $3 \mathrm{f}$ hollow bound $\mathrm{CO}$ (i.e. $\mathbf{h C O 2}, \mathbf{h C O 3}=\mathbf{h C O}(111 / 111)$ ) to the $(111)$ )-like facets, or at the bridge site between two (111)-facets $\left(\mathbf{b C O 3}=\mathbf{b C O}_{(111 / 111)}\right)$. Bridge-bound CO between two (111)-facets has been previously described as the most stable adsorption configuration for CO on alumina-supported Pd NPs [23]. Our calculations suggest that the $3 \mathrm{f}$ hollow bound $\mathrm{CO}$ (i.e. $\mathbf{h C O}(111)$ ) is practically isoenergetic with this for $\theta_{\mathrm{CO}} \rightarrow 0$, in keeping with the previously reported weak facet specificity for $\mathrm{CO}$ adsorption in the low coverage limit [31]. In the following section we briefly evaluate the interaction of two hCO molecules on the $\mathrm{Pd}_{38}$ surface before considering adsorption energetics at higher CO coverages.
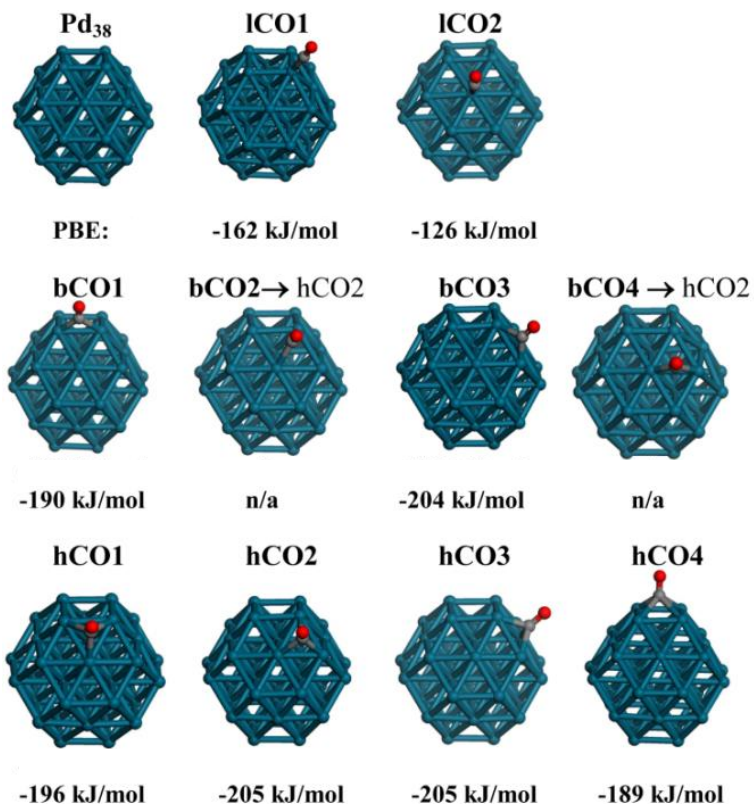

Figure 5. Symmetry unique adsorption sites and energies for $\mathrm{Pd}_{38} \mathrm{CO}$ using the $\mathrm{PBE} \mathrm{XC}$ functional.

3.3. High coverage CO adsorption on Pd38. The influence of lateral interactions and charge sharing upon CO binding to a $\mathrm{Pd}_{38} \mathrm{NP}$ was studied by progressively increasing the number of co-adsorbed molecules. Structures in which two CO molecules were co-adsorbed at $3 \mathrm{f}$ hollow sites on $\mathrm{Pd}_{38}$ were probed first, and a selection of these configurations are presented in Fig. 6. The most favourable scenario for this system is that in which both CO molecules share one Pd atom (i.e. 2hCO1),

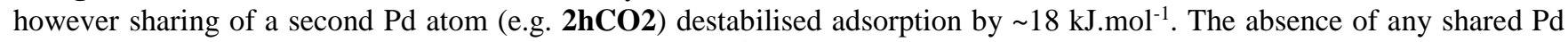
atoms (e.g. 2hCO3) is likewise disfavoured (by $11 \mathrm{~kJ}^{\mathrm{mol}}{ }^{-1}$ ) compared to that wherein a single surface Pd atom is shared.

A similar phenomenon is observed for four co-adsorbed $\mathrm{CO}$ molecules, for which the most stable structures are those in which all CO molecules share a single Pd atom, resulting in a ring of CO molecules around the (100) facet (4COh4 $\mathbf{b}_{0} \mathbf{l o}$ in Fig. 6). The diffusion barrier of $\mathrm{CO}$ on $\mathrm{Pd}(110)$ surfaces determined by inelastic tunneling microcopy is $17.4 \mathrm{~kJ}^{\mathrm{mol}}{ }^{-1}$ [79]. At high coverages, this barrier is expected to fall, according to time-elapsed STM diffusivity studies of $\mathrm{CO}$ on $\mathrm{Cu}(111)$ which showed a doubling in the hopping rate with increasing local CO coverage [80]. Based on our static results above, and assuming fast $\mathrm{CO}$ diffusion kinetics on the NP surface, one would expect that all $3 \mathrm{f}$ hollow sites surrounding the six $4 \mathrm{f}$ hollow sites of $\mathrm{Pd}_{38}$ would be occupied first as the $\mathrm{CO}$ coverage is further increased. We used this concept to create one set of models for predominantly hollow-bound $\mathrm{Pd}_{38}(\mathrm{CO})_{n}$ through algorithm 1. Specifically, algorithm 1 involves: (a) occupy all $3 \mathrm{f}$ hollow sites around one of the six $4 \mathrm{f}$ hollows; then (b) add $\mathrm{CO}$ molecules to $3 \mathrm{f}$ hollow positions around adjacent $4 \mathrm{f}$ hollows while maximising the number of single, shared, Pd atoms between any two adsorbates; and finally (c) perform a full optimisation without symmetry constraints to permit relaxation to other bound configurations. The resulting structures built

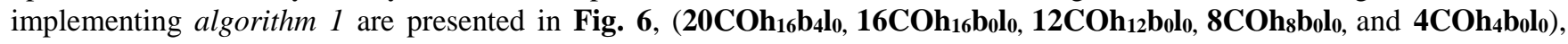


their associated energetics plotted against cluster size in Fig. 7, and more detailed data provided in Table 2. This methodology suggested that, even at the highest coverages, only hollow and bridge sites were occupied in the optimised structures. Using just algorithm 1, linearly-bound $\mathrm{CO}$ would not be sampled, and hence a second approach was also used to produce alternative site occupancies.

The second algorithm adopts a different approach based around the 'domino effect', to model repulsive interactions between high coverages of adjacent, linearly adsorbed $\mathrm{CO}$ molecules, rationalised previously for a $\mathrm{Rh}_{4}(3,1)$ cluster $[16]$ and to simulate low coverage adsorption from a less dense gas phase. Algorithm 2 proceeds as follows: (a) place CO molecules on atop positions with their molecular axes pointing towards the centre of mass of the NP; then (b) adjust bondlengths so that all Pd-C and C-O bonds lengths equal 2.050 and $1.115 \AA$ respectively, to emulate chemisorption from a weakly bound state; and finally (c) perform a full optimisation without symmetry constraints to permit relaxation of linear $\mathrm{CO}$ to bridge and hollow sites. This algorithm was utilised to generate the structures $32 \mathrm{COh}_{10} \mathbf{b}_{7} \mathbf{l}_{15}, \mathbf{2 4 C O h}_{2} \mathbf{b}_{9} \mathbf{l}_{13}, \mathbf{1 2 C O}_{0} \mathrm{C}_{0} \mathbf{l}_{12}, \mathbf{6 C O h}_{0} \mathrm{~b}_{0} \mathbf{l}_{6}$, 4COh $\mathbf{C b}_{0} \mathbf{l}_{4}, 2 \mathrm{COh}_{0} \mathrm{~b}_{0} \mathbf{l}_{2}$ and $\mathrm{COh}_{0} \mathrm{~b}_{0} \mathbf{l}_{1}$, which are also included in Fig. $\mathbf{6}$ and Fig. $\mathbf{7}$ with additional detail in Table 2.

Algorithm 1 was based on observations from low PBE-energy arrangements for two and four CO molecules, wherein all possible adsorption combinations could be easily tested. Algorithm 2 affords an additional test that initially places all CO molecules in the least energetically favourable atop site, such that at low coverages, adsorbate-adsorbate repulsive interactions are weak and $\mathrm{CO}$ molecules are trapped in local minima that prevent their relaxation into lower energy bridge and hollow sites; at high coverages, strong repulsive interactions enable linearly-bound CO to overcome small barriers associated with their movement into bridge or hollow sites, producing configurations in which all three types of adsorption site are populated. Such local energy minima in the DFT calculations are more likely to correspond to the experimental situation, wherein an atop preference should be observed at low coverage.
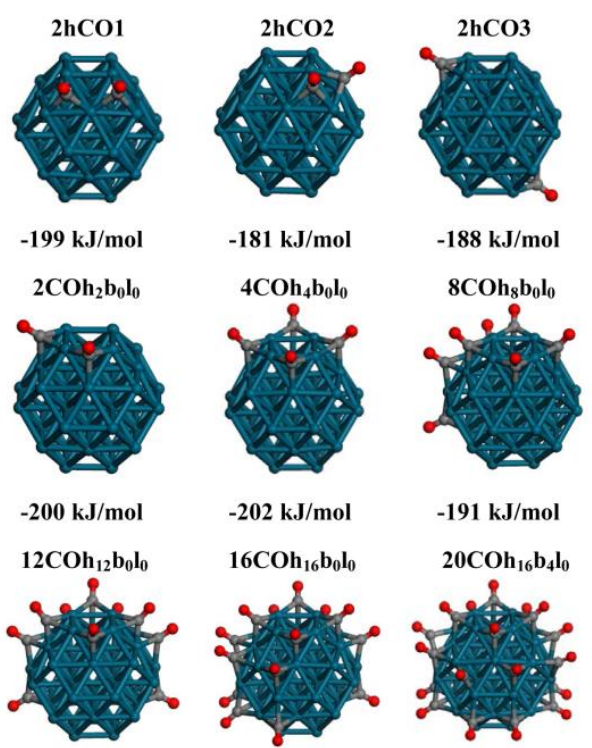

$-191 \mathrm{~kJ} / \mathrm{mol}$

$-186 \mathrm{~kJ} / \mathrm{mol}$
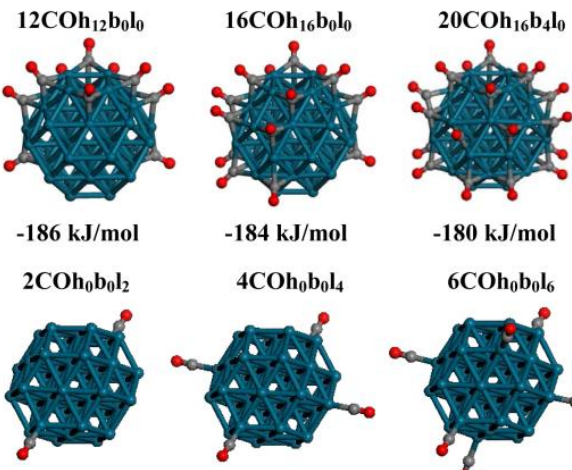

$-184 \mathrm{~kJ} / \mathrm{mol}$

$-180 \mathrm{~kJ} / \mathrm{mol}$
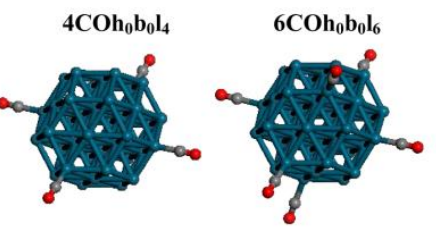

$-165 \mathrm{~kJ} / \mathrm{mol}$

$-165 \mathrm{~kJ} / \mathrm{mol}$

$$
-164 \mathrm{~kJ} / \mathrm{mol}
$$

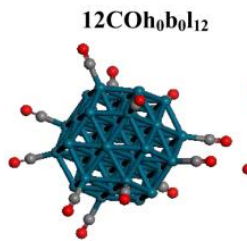

$-165 \mathrm{~kJ} / \mathrm{mol}$

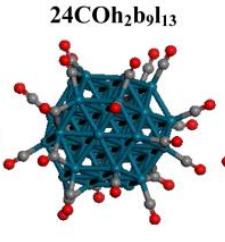

$-165 \mathrm{~kJ} / \mathrm{mol}$

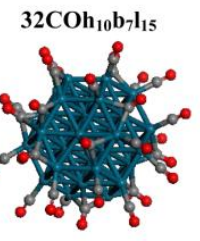

$-158 \mathrm{~kJ} / \mathrm{mol}$

Figure 6. Structures and PBE adsorption energies per $\mathrm{CO}$ molecule of fully relaxed $\mathrm{Pd}_{38}(\mathrm{CO})_{\mathrm{n}}$, where $\mathrm{n}=2,4,6,8,12,16,20,24,32$. Initial geometries obtained with coverage algorithms 1 and 2 . 
Fig. 7 shows that at low coverages algorithm 2 yields much less favourable DFT adsorption energies than algorithm 1, since the former preserves as many as 12 linearly-bound $\mathrm{CO}$ molecules, whereas only hollow sites are occupied postrelaxation via the latter approach (see Table 2). We note that the adsorption energy per $\mathrm{CO}$ molecule weakens with increasing $\theta_{\mathrm{CO}}$ for algorithm 1, but remains constant for algorithm 2 . The coverage-dependent adsorption energy predicted by algorithm 1 is in good agreement with microcalorimetric measurements of CO on supported model Pd NPs [31, 32, 81], which show a 20-40 kJ.mol ${ }^{-1}$ decrease with $\theta_{\mathrm{CO}}$, and previous calculations on a Rh nanocluster which showed a $60 \mathrm{~kJ}^{-\mathrm{mol}^{-1}}$ fall in the heat of $\mathrm{CO}$ adsorption with coverage [16]. Microcalorimetric measurements of the heats of $\mathrm{CO}$ adsorption on $\mathrm{Pd} / \mathrm{Al}_{2} \mathrm{O}_{3}, \mathrm{SiO}_{2}$ and $\mathrm{TiO}_{2}$ having loadings of 2, 5 and $10 \mathrm{wt} \% \mathrm{Pd}$ reported values spanning 99-162 kJ.mol ${ }^{-1}$ [30], with high adsorption energies associated with low Pd loadings (i.e. smaller) and highly reduced particles. Our calculated, average CO adsorption energy of $-159 \pm 1 \mathrm{~kJ} \cdot \mathrm{mol}^{-1}$ on $\mathrm{Pd}_{38}$ for $\theta=1$ is in good agreement with the $-162 \mathrm{~kJ} \cdot \mathrm{mol}^{-1}$ measured by Dropsch and Baerns [30]. We have also explored two higher coverage regimes, $\operatorname{Pd}_{38}(\mathrm{CO})_{38}(\theta=1.50)$ and $\operatorname{Pd}_{38}(\mathrm{CO})_{54}(\theta=1.69)$, which yielded even lower heats of adsorption of $-123.0 \mathrm{~kJ} \cdot \mathrm{mol}^{-1}$ and $-112.4 \mathrm{~kJ}^{\mathrm{mol}}{ }^{-1}$ respectively.

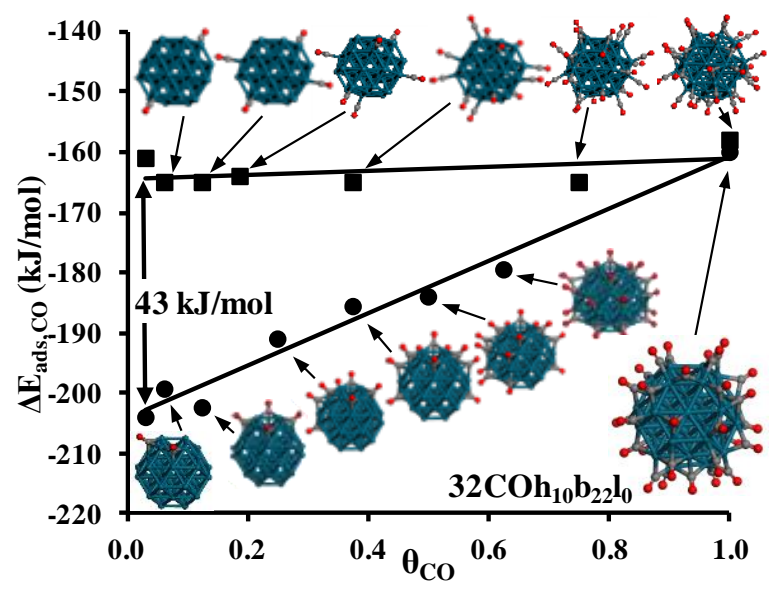

Figure 7. Coverage dependent $\mathrm{CO}$ adsorption energy ( $\triangle \mathrm{E}$ ads,Co, $\mathrm{PBE})$ per molecule over cubooctahedral $\mathrm{Pd}_{38}$ for structures obtained via $(\bullet)$ algorithm 1 and (a) algorithm 2, and for $\mathbf{3 2} \mathbf{C O h}_{\mathbf{1 0}} \mathbf{b}_{\mathbf{2} 2 \mathbf{l}} \mathbf{l}$. Solid lines are least square fits to data points.

Table 2. Adsorption energy per $\mathrm{CO}$ on a $\mathrm{Pd}_{38} \mathrm{NP}$ as a function of $\mathrm{CO}$ coverage and adsorption site.

\begin{tabular}{|c|c|c|c|c|c|c|}
\hline Label $^{a}$ & formula & $\theta \mathrm{co}^{b}$ & $\Delta \mathbf{E}_{\mathrm{ads}, \mathrm{Co}}{ }^{c}$ & $\mathbf{n}_{\mathrm{hCO}}$ & $\mathbf{n}_{\mathbf{b C O}}$ & $\mathbf{n}_{\text {ICO }}$ \\
\hline $32 \mathrm{COh}_{10} \mathrm{~b}_{22} \mathrm{l}_{0}$ & $\mathrm{Pd}_{38}(\mathrm{CO})_{32}$ & 1.000 & -160 & 10 & 22 & 0 \\
\hline $20 C_{16} b_{4} l_{0}$ & $\mathrm{Pd}_{38}(\mathrm{CO})_{20}$ & 0.625 & -180 & 16 & 4 & 0 \\
\hline $16 \mathrm{COh}_{16} \mathrm{~b}_{0} \mathrm{l}_{0}$ & $\mathrm{Pd}_{38}(\mathrm{CO})_{16}$ & 0.500 & -184 & 16 & 0 & 0 \\
\hline 12COh$_{12} \mathrm{~b}_{0} \mathbf{l}_{0}$ & $\mathrm{Pd}_{38}(\mathrm{CO})_{12}$ & 0.375 & -186 & 12 & 0 & 0 \\
\hline 8COhsbolo & $\mathrm{Pd}_{38}(\mathrm{CO})_{8}$ & 0.250 & -191 & 8 & 0 & 0 \\
\hline $4 \mathrm{COh}_{4} \mathrm{~b}_{0} \mathrm{l}_{0}$ & $\mathrm{Pd}_{38}(\mathrm{CO})_{4}$ & 0.125 & -202 & 4 & 0 & 0 \\
\hline $2 \mathrm{COh}_{2} \mathrm{~b}_{0} \mathrm{l}_{0}$ & $\mathrm{Pd}_{38}(\mathrm{CO})_{2}$ & 0.063 & -199 & 2 & 0 & 0 \\
\hline COh$_{1} b_{0} l_{0}$ & $\mathrm{Pd}_{38}(\mathrm{CO})_{1}$ & 0.031 & -204 & 1 & 0 & 0 \\
\hline 32COh $10 b_{7} l_{15}$ & $\mathrm{Pd}_{38}(\mathrm{CO})_{32}$ & 1.000 & -158 & 10 & 7 & 15 \\
\hline $24 \mathrm{COh}_{2} \mathrm{~b}_{9} \mathrm{l}_{13}$ & $\mathrm{Pd}_{38}(\mathrm{CO})_{24}$ & 0.750 & -165 & 2 & 9 & 13 \\
\hline $12 \mathrm{COh}_{0} \mathrm{~b}_{0} \mathrm{l}_{12}$ & $\mathrm{Pd}_{38}(\mathrm{CO})_{12}$ & 0.375 & -165 & 0 & 0 & 12 \\
\hline 6COhobols & $\mathrm{Pd}_{38}(\mathrm{CO})_{6}$ & 0.188 & -164 & 0 & 0 & 6 \\
\hline $4 \mathrm{COh}_{0} \mathrm{~b}_{0} \mathrm{l}_{4}$ & $\mathrm{Pd}_{38}(\mathrm{CO})_{4}$ & 0.125 & -165 & 0 & 0 & 4 \\
\hline $2 \mathrm{COh}_{0} \mathrm{~b}_{0} \mathrm{l}_{2}$ & $\mathrm{Pd}_{38}(\mathrm{CO})_{2}$ & 0.063 & -165 & 0 & 0 & 2 \\
\hline \multirow[t]{2}{*}{ ICO1 } & $\mathrm{Pd}_{38}(\mathrm{CO})_{1}$ & 0.031 & -161 & 0 & 0 & 1 \\
\hline & $\mathrm{Pd}_{38}$ & 0.000 & - & - & - & - \\
\hline
\end{tabular}


${ }^{a}$ Entries 2-8 and 9-15 have been calculated via algorithm 1 and 2, respectively.

${ }^{b} \mathrm{CO}$ surface coverage given by $\mathrm{n}_{\mathrm{CO}} / \mathrm{n}_{\text {surf }}$, where $\mathrm{n}_{\text {surf }}=32$ for $\mathrm{Pd}_{38}$

${ }^{c}$ Adsorption energy change per $\mathrm{CO}$ in $\mathrm{kJ} / \mathrm{mol}$ calculated using Eqn. 1

It is interesting to note that (at low coverages) $\mathrm{CO}$ bound in hollow sites is up to $43 \mathrm{~kJ} \cdot \mathrm{mol}^{-1}$ more stable than that adsorbed in linear sites. However, this large energetic difference between linear and hollow bound $\mathrm{CO}$ vanishes at higher coverages

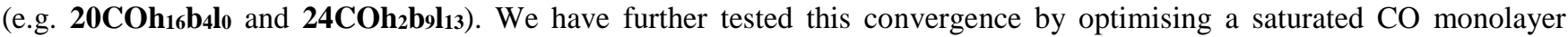
structure (32COh $\mathbf{C O}_{10} \mathbf{b}_{7} \mathbf{l}_{15}$, see Table 3). For this limiting coverage regime, the energy difference per CO molecule for different configurations (e.g. 32COh $\mathbf{C h}_{10} \mathbf{b}_{22} \mathbf{l}_{0}$ versus $\left.\mathbf{3 2} \mathbf{C O h}_{10} \mathbf{b}_{7} \mathbf{l}_{15}\right)$ falls below the threshold of thermal diffusion at STP $\left(<2.5 \mathrm{~kJ} \mathrm{~mol}^{-1}\right)$, suggesting that adsorption site populations will be fluxional as $\mathrm{CO}$ coverage nears saturation. Explicit calculation of the diffusion barrier at $\theta=1$ was not possible due to the coupled diffusion of $C O$ molecules on Pd NP at high coverages. For example, for $\mathbf{3 2} \mathbf{C O h}_{12} \mathbf{b}_{7} \mathbf{l}_{13}$, the movement of one of the linearly-bound $\mathrm{CO}\left(\mathrm{lC}_{23} \mathrm{O}_{10}\right.$, see ESI for atom labels) to a nearby hollow-bound position causes the simultaneous relaxation of $\mathrm{hC}_{7} \mathrm{O}_{14}$ to bCO and $1 \mathrm{C}_{30} \mathrm{O}_{31}$ to bCO. In another case (32CO'h12 $\mathbf{b}_{7} \mathbf{l}_{13}$ ), movement of $\mathrm{bC}_{22} \mathrm{O}_{28}$ to a hollow site causes the simultaneous relaxation of $1 \mathrm{C}_{6} \mathrm{O}_{13}$ and $1 \mathrm{C}_{18} \mathrm{O}_{7}$ to hollows, and $1 \mathrm{CO}_{13} \mathrm{O}_{3}$ to a bridge site. In all cases examined, displacement of a single $\mathrm{CO}$ molecule triggered site-switching of multiple other co-adsorbates; the $\mathrm{CO}$ molecules so perturbed were not necessarily neighbouring the initially displaced $\mathrm{CO}$ molecule, but on occasion on the opposite side of the NP. Table 3 shows that the structures resulting from these displacements have close relative energies despite significant differences in their site populations. Experimental IR spectra of CO over Pd nanoparticles are measured almost exclusively at 'high' pressure/saturation $\theta_{\mathrm{CO}}[15,23,82-84]$, hence it seems plausible that algorithm 2, which incorporates repulsive interactions between co-adsorbates and generates linear, bridge and hollow CO species, may be the most apposite among the 2 algorithms for simulating IR spectra of such Pd NP systems. Indeed, we later show that simulated IR absorption spectra using algorithm 2 are in good agreement with experimental data for silica supported palladium NPs.

Table 3. Relative average $\mathrm{CO}$ adsorption energy as a function of adsorption site population at $\theta_{\mathrm{CO}}=1$

\begin{tabular}{|c|c|c|c|c|c|}
\hline Label & $\mathbf{r} \Delta \mathbf{E}_{\mathrm{ads}}{ }^{a}$ & $\mathbf{n}_{\mathrm{hCO}}$ & $\mathbf{n}_{\mathbf{b C O}}$ & nico & action \\
\hline $\mathbf{3 2 C O h}_{10} \mathrm{~b}_{7} \mathbf{l}_{15}$ & 0.0 & 10 & 7 & 15 & original \\
\hline $32 \mathrm{COh}_{12} \mathbf{b}_{7} \mathbf{l}_{13}$ & 0.1 & 12 & 7 & 13 & $1 \mathrm{CO}$ to $\mathrm{hCO}$ \\
\hline $32 \mathbf{C O}^{\prime} \mathbf{h}_{12} \mathbf{b}_{7} \mathbf{l}_{13}$ & -1.0 & 12 & 7 & 13 & $\mathrm{bCO}$ to $\mathrm{hCO}$ \\
\hline $\mathbf{3 2 C O h}_{11} \mathrm{~b}_{91} \mathrm{l}_{12}$ & -1.9 & 11 & 9 & 12 & $1 \mathrm{CO}$ to $\mathrm{bCO}$ \\
\hline $3_{2} \mathrm{COh}_{10} \mathrm{~b}_{22} \mathbf{l}_{0}$ & -2.3 & 10 & 22 & 0 & all $1 \mathrm{CO}$ to bCO \\
\hline
\end{tabular}

Dropsch and Baerns also obtained coverage-dependent TPD-CO spectra that show a shift to lower temperature as a function of $\mathrm{CO}$ coverage, consistent with the falling heats of $\mathrm{CO}$ adsorption observe in Fig. 7 [30]. At coverages <0.4 ML they only observed one $\mathrm{CO}$ desorption peak, while higher coverages resulted in three distinct adsorption states, consistent with the computed thermodynamic stability of hollow-bound $\mathrm{CO}$ at low coverage, and population of three bonding sites at $\theta_{\mathrm{CO}}=1$ as noted above. This TPD study also concluded that bridge-bound CO was the most abundant form over Pd NPs. From a thermodynamic viewpoint our calculations yield a similar conclusion, with the lowest energy structure for $\mathrm{Pd}_{38}(\mathrm{CO})_{32}$ comprising mostly bridge-bound CO (i.e. 32COh $\mathbf{1 0 b}_{22} \mathbf{l}$ ), and a minority hollow-bound. High CO coverages appear to energetically favour chains of bridged molecules, which may be closed, or as in this work, terminated by linear carbon monoxide (Scheme 1). Such chains of bridging CO molecules decorate the edges of the $\mathrm{Pd}_{38}\left(\mathrm{O}_{\mathrm{h}}\right)$ cubooctahedron, in line with high pressure (200 mbar) SFG studies which showed the existence of such CO species under catalytically relevant reaction conditions [23]. 
(a)<smiles>CC(C)C(=O)NC(=O)NC(=O)C(C)(C)C</smiles>

(b)<smiles>[M]C(N)=NC(=O)[M]C(=O)N=C=O</smiles>

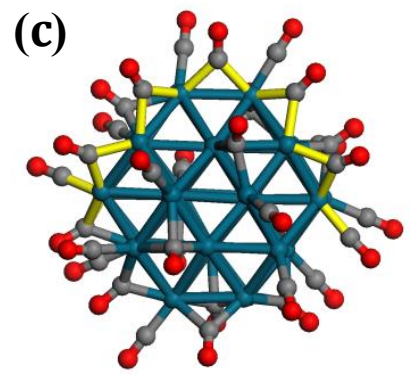

Scheme 1. Schematic of (a) closed and (b) open bridge-bound CO chains on a $\mathrm{Pd}_{38} \mathrm{NP}$, and (c) three-dimensional ball and stick representation of $\mathrm{Pd}_{38}(\mathrm{CO})_{32}$ showing open bridge $\mathrm{CO}$ chain in yellow.

It is conceivable that the motion in such $\mathrm{CO}$ chains is coupled, and indeed our subsequent vibrational analysis suggests that frequency-splitting occurs, demonstrating vibrational coupling of $\mathrm{CO}$ stretches; such splitting/shifting of $\mathrm{CO}$ vibrational bands has been previously reported on surfaces [85] and metal NPs [18]. Other thermodynamically stable structural motifs were also identified. For example, 1CO-hCO-lCO and even 1CO-hCO-lCO-hCO-lCO appeared in the optimised structures to have greater thermodynamic stability than isolated adsorbed $\mathrm{CO}$ configurations which one may have expected on the basis of reducing repulsive inter-adsorbate interactions.

3.4. IR simulations of $\mathbf{P d}_{38}(\mathbf{C O})_{n}$. At the PBE level, using a $30 \AA$ cubic periodic box, the calculated vibrational frequency of gas phase $\mathrm{CO}$ is $v_{\mathrm{CO}, \mathrm{PBE}}=2131 \mathrm{~cm}^{-1}$ which is $49 \mathrm{~cm}^{-1}$ below the experimental value $\left(v_{\exp }=2180 \mathrm{~cm}^{-1}\right)$ [18]. We therefore add $49 \mathrm{~cm}^{-1}$ to the calculated vibrational frequencies for the PBE simulations using $\mathrm{CO}$ on the $\mathrm{Pd}_{38}$ cluster to make easier comparison with experimental data. IR simulations based on these intensity estimates from B3LYP calculations of the smaller clusters where carried out using optimised structures from algorithm $1\left(\mathbf{2 0 C O h}_{16} \mathbf{b}_{4} \mathbf{l}_{\mathbf{0}}, \mathbf{1 6}_{\mathbf{6}} \mathrm{COh}_{16} \mathbf{b}_{0} \mathbf{l}_{\mathbf{0}}, \mathbf{1 2 C O h}_{12} \mathbf{b}_{\mathbf{0}} \mathbf{l}_{\mathbf{0}}\right.$,

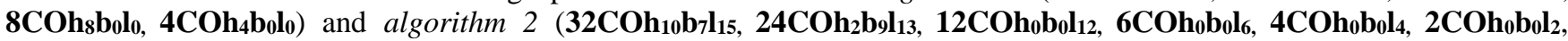
COhobol1). Simulated spectra are shown in Fig. 8a-b, alongside a comparative experimental DRIFTS spectrum for CO adsorbed over a $2.22 \mathrm{wt} \%$ Pd/KIT-6 mesoporous catalyst, with mean Pd NP diameter of $1.7 \mathrm{~nm}$ (Fig. 8c).

IR spectra simulated via algorithm 1 display significant vibrational coupling, evidenced by fine structure within the hollow-bound CO band, which (albeit infrequently present) appears as a weak, broad feature in DRIFT spectra of supported catalysts [18]. Fig. 8a also shows the presence of bridge-bound $\mathrm{CO}$ at intermediate coverages $\left(\theta_{\mathrm{CO}}=0.625\right)$, which overlaps with hollow $\mathrm{CO}$ features, indicative of similar adsorption energetics at high coverage. The latter observation is consistent with the weakening Pd-hCO bond with increasing $\theta_{\mathrm{CO}}$ from $0.03 \rightarrow 0.625$ apparent in Fig. 7, which induces a pronounced $63 \mathrm{~cm}^{-1}$ blue-shift in the hCO band average position. A similar, albeit, weaker blue-shift $\left(29 \mathrm{~cm}^{-1}\right.$, Fig. 8b) was observed with increasing $\theta_{\mathrm{CO}}$ for linearly-bound $\mathrm{CO}$ bands simulated via algorithm 2 .

The utility of these simulations was assessed for $\mathrm{Pd}_{38}(\mathrm{CO})_{32}$ by benchmarking against frequency ranges and band assignment for RAIRS studies on model $\mathrm{Pd} / \mathrm{Al}_{2} \mathrm{O}_{3}$ catalysts [86] and vibrational sum frequency generation (SFG) of CO adsorption on Pd NPs and Pd(111) surfaces [39]. The RAIRS study of Wolter et al recorded absorption spectra for CO on nanoparticles ranging from $\mathrm{Pd}_{<10}$ to $\mathrm{Pd}_{7100}$ at 90 and $300 \mathrm{~K}$. Features between $1930-2000 \mathrm{~cm}^{-1}$ were assigned to bridge-bound $\mathrm{CO}$, and those between $2090-2120 \mathrm{~cm}^{-1}$ to linearly-bound CO. These compare extremely favourably to corresponding predictions of 1920-1983 $\mathrm{cm}^{-1}$ and 2062-2106 $\mathrm{cm}^{-1}$ from our simulations using algorithm 2 (Fig. 8b). The signal from hollow $\mathrm{CO}(\mathrm{hCO})$ was reported to be weak in these RAIRS experiments, however photoelectron diffraction studies [27] and RAIRS measurements over $\mathrm{Pd}(111)$ at temperatures $<200 \mathrm{~K}$ and $>350 \mathrm{~K}$ [87] suggest an indicative stretching frequency between $1825-1900 \mathrm{~cm}^{-1}$ (cf. 1843-1898 $\mathrm{cm}^{-1}$ in Fig. 8c). Agreement between the present calculations at $\theta_{\mathrm{CO}}=1$ via algorithm 2 and experimental observations is astonishingly good. Band positions and relative intensities of linear and bridge-bound $\mathrm{CO}$ from our simulations are also in excellent correspondence with the DRIFT spectrum of a saturated CO adlayer over a $2.22 \mathrm{wt} \%$ Pd/KIT-6 catalyst [15] (Fig. 8c). The extremely weak experimental hCO band for Pd NPs supported on the KIT-6 mesoporous silica likely reflects a combination of (i) the smaller IR absorption coefficients with respect to bCO and ICO (Fig. 4), and (ii.) the experimental protocol, in which the Pd catalyst was flushed with an inert gas after CO adsorption at 298 
$\mathrm{K}$ prior to spectral acquisition [15]; thermodynamics suggest that $\mathrm{CO}$ is only stable in hollow sites at ambient temperature under CO partial pressures exceeding 1000 mbar [87].
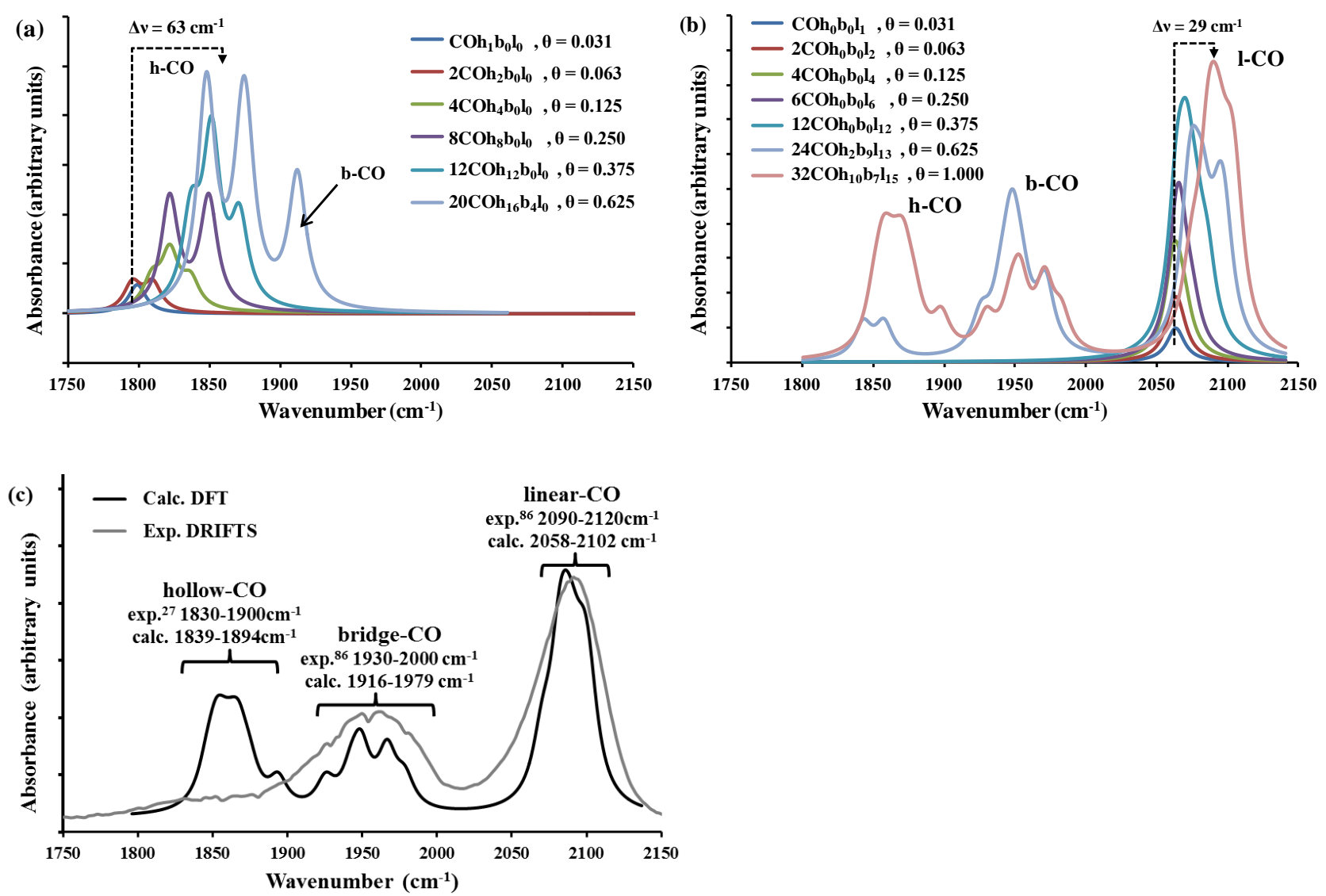

Figure 8. Simulated IR absorption spectra for a range of $\mathrm{Pd}_{38}(\mathrm{CO})_{\mathrm{n}}$ structures created with (a) algorithm 1, (b) algorithm 2 and (c) comparison of algorithm 2 with experimental DRIFTS spectrum of CO on Pd/KIT-6 for $\theta_{\mathrm{CO}}=1$. Oscillator intensities scaled in the ratio lCO:bCO:hCO $=1.00: 0.68: 0.58$ taken from $\mathrm{Pd}_{13}$ in Fig. 4. Frequencies have been shifted by $49 \mathrm{~cm}^{-1}$ which is the difference between the calculated vibrational frequency of gas phase $\mathrm{CO}\left(v_{\mathrm{CO}, \mathrm{PBE}}=2131 \mathrm{~cm}^{-1}\right)$ and the experimental value $\left(v_{\exp }=2180 \mathrm{~cm}^{-1}\right)[18]$.

3.5. Coverage-dependent blue-shift of $\mathrm{CO}$ on $\mathrm{Pd} \mathbf{3 8}$. The preceding coverage-dependent vibrational frequencies for $\mathrm{CO}$ in each of the three adsorption sites over a $\operatorname{Pd}_{38}\left(\mathrm{O}_{\mathrm{h}}\right) \mathrm{NP}$ derived via algorithms 1 and 2 are summarised in Fig. 9. In all cases, the $\mathrm{CO}$ stretch exhibited a significant blue-shift with increasing coverage, with the sensitivity of this shift in the order hCO > $\mathrm{bCO}>1 \mathrm{CO}$, akin to that observed in electrochemical RAIRS studies of CO adlayers on Pd(110), which demonstrated a 10 $\mathrm{cm}^{-1}$ blue-shift for $\theta_{\mathrm{CO}}=0 \rightarrow 1$ [88]. We attribute the stronger coverage-dependence observed herein to quantum size effects, and note that an earlier study of $\mathrm{CO}$ adsorption on $\mathrm{Rh}_{4}(3,1)$ reported an even greater blue-shift of $80 \mathrm{~cm}^{-1}[16]$. The coveragedependent blue-shift may therefore provide a means by which to differentiate between hollow and bridge/linear bound CO in experimental IR spectroscopy. This consistent blue-shift for all adsorption configurations indicates strengthening of the $\mathrm{C}-\mathrm{O}$ bond, and concurrent weakening of the M-CO bond. Based on the Blyholder [77] and Bagus [89] interpretations of the metal-carbonyl bond, this weakening reflects reduced electron donation from occupied d-states on the metal into the doubly degenerate, anti-bonding $2 \pi^{*}$ molecular orbital of $\mathrm{CO}$, increasing the covalency of the $\mathrm{C}=\mathrm{O}$ bond and hence force constant. 

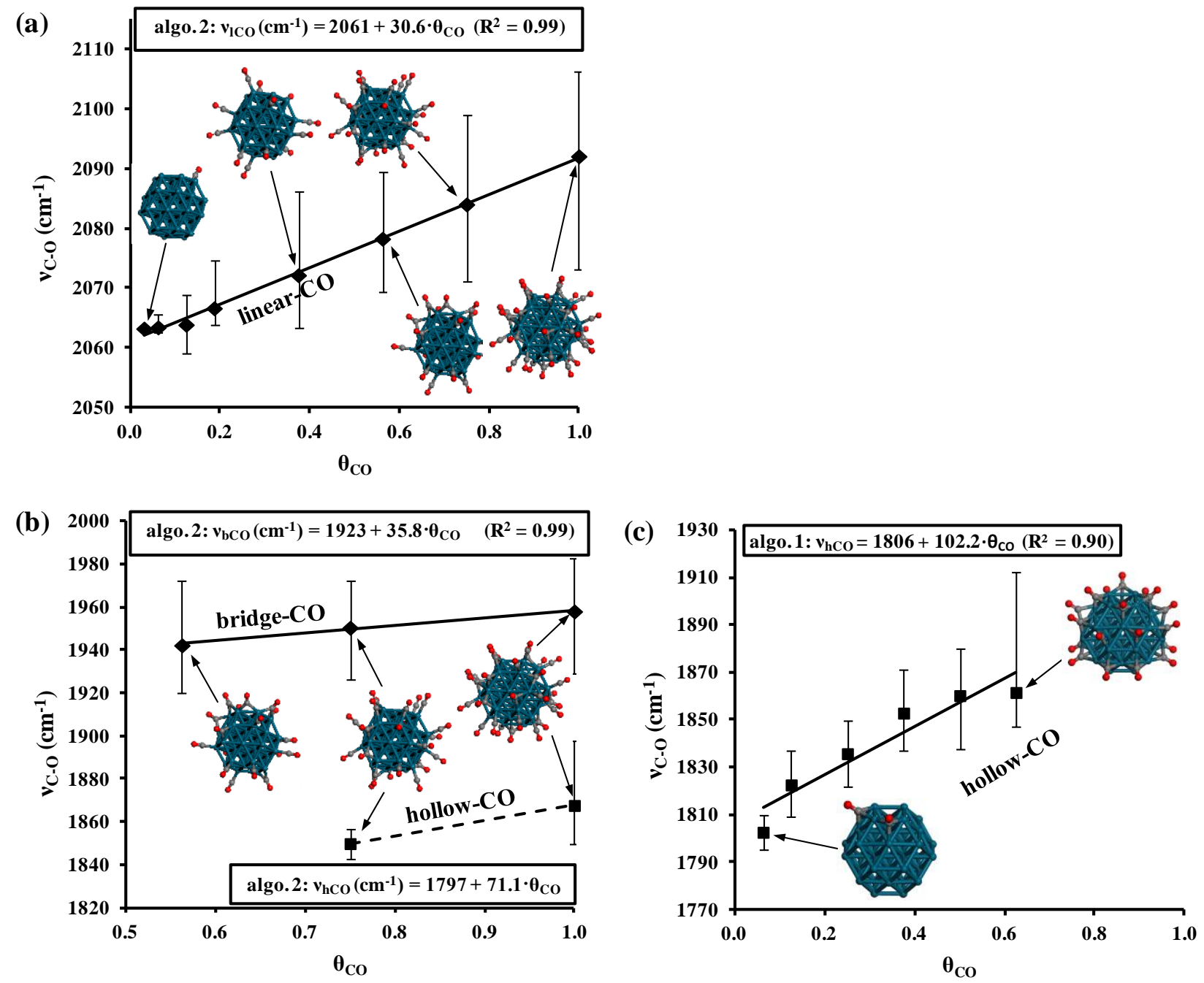

Figure 9. Mean CO vibrational stretching frequency of (a) linear and (b) bridge (-) and hollow (---) bound CO from algorithm 2, and (c) hollow bound $\mathrm{CO}$ from algorithm 1, as a function of $\theta_{\mathrm{CO}}$ on a $\mathrm{Pd}_{38} \mathrm{NP}$. Error bars show the maximum/minimum values.

3.6. Coverage-dependent isotropic expansion of Pd38. Adsorbate-induced lattice expansion is well known for extended surfaces and NPs through diffraction studies [90], and has been demonstrated computationally for hydrogen on $\mathrm{Pd}_{6}$ and $\mathrm{Pd}_{13}$ NPs [91]. In view of the above variation in CO adsorption strength with coverage, we therefore computed the mean Pd-Pd bondlength $\left(\mathrm{r}_{<\mathrm{Pd}-\mathrm{Pd}>}\right)$ and accompanying variance $\left(\sigma_{<\mathrm{Pd}-\mathrm{Pd}>}\right)$ in order to identify whether a similar lattice expansion occurs in the $\mathrm{Pd}_{38}(\mathrm{CO})_{\mathrm{n}}$ system. Results of this analysis are shown in Fig. 10 for structures obtained via algorithms 1 and 2 . The average Pd-Pd bondlength of the $\mathrm{Pd}_{38} \mathrm{NP}$ increased by $>3.5 \%$ as $\theta_{\mathrm{CO}}=0 \rightarrow 1$, a striking lattice expansion that was approximately proportional to the number of adsorbed $\mathrm{CO}$ molecules. The origin of this expansion lies in the overall increase in charge transfer from the $\mathrm{Pd}_{38} \mathrm{NP}$ into adsorbate bonds with increasing $\mathrm{CO}$ coverage, and hence weaker cohesive metallic bonding. It is important to note that while the adsorption energy per CO molecule falls with $\theta_{\text {Co }}$ from approximately -200 $\mathrm{kJ} . \mathrm{mol}^{-1}$ over the bare particle to $-160 \mathrm{~kJ}^{-\mathrm{mol}^{-1}}$ at saturation, this is more than compensated for by the increasing number of Pd-CO bonds formed, and hence rise in total adsorption energy and consequent perturbation of the intraparticle bonding. Structures derived by algorithm 1 always exhibited larger expansions than those derived by algorithm 2, although the associated spread of bondlengths $\sigma_{<\mathrm{Pd}-\mathrm{Pd}}>$ was also greater. Both these observations are consistent with stronger bonding of hollow versus linearly-bound $\mathrm{CO}$, and hence larger perturbation of the underlying $\mathrm{Pd}_{38} \mathrm{NP}$ framework. Algorithms 1 and 2 predict significantly different sensitivities of $\mathrm{r}_{<\mathrm{Pd}-\mathrm{Pd}>}$ to $\theta_{\mathrm{CO}}$, providing an avenue for experimentally testing whether $\mathrm{CO}$ adsorption commences via all hollow (algorithm 1) or mixed adsorption (algorithm 2) structures via e.g. coverage dependent EXAFS, one of the few techniques able to precisely measure interatomic distances of sub- $2 \mathrm{~nm}$ NPs under reactive environments. This observation may also explain the low population of the hollow site usually seen experimentally (e.g. in the DRIFTS spectrum of Fig. 8 ). The $\mathrm{Pd}_{38}$ cluster used in our calculations is at the smaller length scale of those generally 
prepared experimentally, and likely exhibits greater surface flexibility than larger clusters, more readily accommodating the Pd-Pd bond expansion required for hollow site occupation.

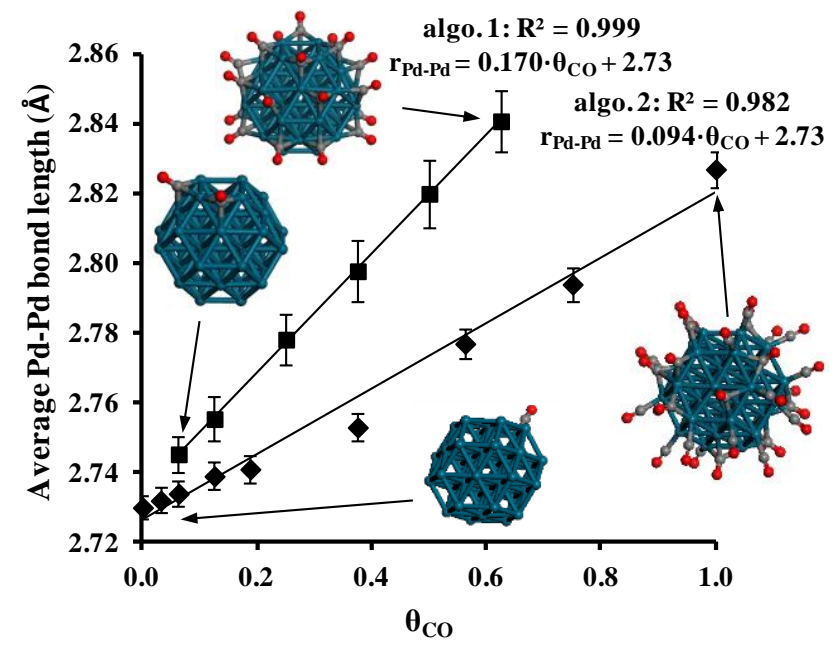

Figure 10. Mean Pd-Pd bondlength of $\mathrm{Pd}_{38} \mathrm{NP}$ as a function of CO coverage. Error bars show the standard deviation.

The narrow distribution of Pd-Pd bondlengths observed for each CO coverage, evidenced by the small values of $\sigma_{<\mathrm{Pd}-\mathrm{Pd}>}$ in Fig. 10, strongly indicates that the $\mathrm{Pd}_{38} \mathrm{NP}$ lattice expansion is isotropic. From a catalytic perspective, the implication is that variations in surface $\mathrm{CO}$ coverage under reaction conditions could systematically regulate isotropic expansion/contraction of palladium NPs, and hence influence molecular co-adsorption, bond activation and ultimately both activity and selectivity (as is reported for $\mathrm{O}$ and $\mathrm{CO}$ adsorption and $\mathrm{CO}$ dissociation over $\mathrm{Ru}(0001)$ [92] wherein DFT calculations of Mavrikakis et al demonstrate an increase in surface reactivity with lattice expansion). Coverage-dependent CO DRIFTS studies would offer another means to experimentally verify our predicted lattice expansion of palladium nanoparticles, since Fig. 8 suggests this occurs concomitant with a 63 and $29 \mathrm{~cm}^{-1}$ blue-shift in the respective hCO and $1 \mathrm{CO}$ bands, with the latter a strong feature of experimental $\mathrm{CO}$ absorption spectra.

\section{CONCLUSIONS}

B3LYP and PBE DFT calculations have been combined to obtain information on IR spectroscopic adsorption frequencies and intensities for $\mathrm{CO}$ chemisorption over $\mathrm{Pd}$ nanoparticles as a function of particle size (i.e. $\mathrm{Pd}_{4}, \mathrm{Pd}_{13}$ and $\left.\mathrm{Pd}_{38}\right)$ and $\mathrm{CO}$ coverage. IR absorption spectra were subsequently simulated for a $\mathrm{Pd}_{38}$ nanoparticle, employing two computational approaches to obtain optimised $\mathrm{Pd}_{38} \mathrm{CO}_{\mathrm{n}}$ structures. Calculated IR spectra using the B3LYP XC-functional to estimate the IR intensities, and PBE to give estimated frequencies, are in good agreement with experimental DRIFTS spectrum for CO adsorption over 2.22\% Pd nanoparticles supported on a KIT-6 silica [15] provided a mixed population of hollow, bridge and atop species are included, and RAIRS and SFG studies of model Pd nanoparticle catalysts [39, 86]. At low coverages $(\theta \rightarrow$ 0 ) we find adsorption energy trends in good agreement with earlier work, and show that the dependence on particle size depends on adsorption site, with hollow and bridge sites showing adsorption energies that are more favourable on small clusters, and linear sites showing a weakening in adsorption as cluster size decreases. At high CO coverages $(\theta=1)$ linearly, bridge- and hollow-bound $\mathrm{CO}$ co-exist, with very small energy differences between alternative arrangements of $\mathrm{CO}$ molecules at different adsorption sites. Diffusion between sites is then thermally feasible at STP via a coupled diffusion process, and the equilibrium arrangement may be influenced by the additional entropy of occupying different sites. Elevated coverages of $\mathrm{CO}$ favour the formation of bridge-bound $\mathrm{CO}$ chains over a $\mathrm{Pd}_{38}$ nanoparticle, with some hollow-bound $\mathrm{CO}$. A coverage-dependent spectroscopic blue-shift is predicted in the vibrational IR bands of adsorbed CO, coincident with an isotropic $3.5 \%$ expansion of the palladium nanoparticle framework, which could a factor in driving adsorption-induced enhancements in catalytic activity for reactions involving CO.

\section{AUTHOR INFORMATION}

\section{Corresponding Authors}

*Constantinos $\quad$ D. Zeinalipour-Yazdi, E-mail: c.zeinalipour-yazdi@ucl.ac.uk; David J. Willock, E-mail: WillockDJ@cardiff.ac.uk; and Adam F. Lee, E-mail: A.F.Lee@aston.ac.uk

\section{Author Contributions}

The manuscript was written through contributions of all authors. 
We thank the EPSRC (EP/E046754/1; EP/G007594) for financial support and the award of a leadership fellowship (AFL).

\section{ACKNOWLEDGMENT}

This work used the ARCHER UK National Supercomputing Service (http://www.archer.ac.uk), Wales' national supercomputing service provider, High Performance Computing (HPC) Wales, and the ARCCA HPC Cluster (Raven). Dr. Christopher Parlett (Aston University) is thanked for providing a DRIFT spectrum of CO adsorbed over a 2.22\% Pd/KIT-6 catalyst.

\section{SUPPORTING INFORMATION}

The relative energy of $\mathrm{Pd}_{4}(3,1)$ using various XC-functionals (S-Fig. 1) and the adsorption energies and vibrational frequencies for CO on $\mathrm{Pd}_{38}$ using PBE and B3LYP (S-Table 1) as well as the Cartesian coordinates (S-Table 2) of all optimized models are provided as supporting information. The correlation of $\mathrm{Pd}_{38} \mathrm{NP}$ isotropic expansion with $\mathrm{CO}$ vibrational frequency is shown in S-Fig. 2.

\section{ABBREVIATIONS}

IR, infrared; UHV, ultra-high vacuum; DFT, density functional theory; DRIFTS, Diffuse reflectance infrared Fouriertransform spectroscopy; TPD, temperature-programmed desorption; MCSCF, multi-configurational self-consistent-field; RAIRS, reflection absorption infrared spectroscopy; SCE, Saturated calomel electrode; SFG, sum-frequency generation; IRMPD; Infrared multiple photon dissociation.

\section{REFERENCES}

[1] M.S. Chen, Y. Cal, Z. Yan, K.K. Gath, S. Axnanda, D.W. Goodman, Highly active surfaces for CO oxidation on rh, pd, and pt, Surf. Sci., 601 (2007) 5326-5331.

[2] A. Haynes, Chapter 1 - Catalytic Methanol Carbonylation, in: C.G. Bruce, K. Helmut (Eds.) Advances in Catalysis, Academic Press, 2010, pp. 1-45.

[3] R. Franke, D. Selent, A. Börner, Applied Hydroformylation, Chemical Reviews, 112 (2012) 5675-5732.

[4] R.J. Behm, K. Christmann, G. Ertl, M.A. Van Hove, Adsorption of CO on Pd(100), J. Chem. Phys., 73 (1980) 2984-2995.

[5] P.J. Berlowitz, C.H.F. Peden, D.W. Goodman, Kinetics of Carbon Monoxide Oxidation on Single-Crystal Palladium, Platinum, and Iridium, J. Phys. Chem., 92 (1988) 5213-5221.

[6] T. Engel, G. Ertl, A Molecular Beam Investigation of the Catalytic Oxidation of CO on Pd (111) J. Chem. Phys., 69 (1978) 1267.

[7] T. Engel, G. Ertl, Elementary Steps in the Catalytic Oxidation of Carbon Monoxide on Platinum Metals, Adv. Catal., 28 (1979) 1-78.

[8] A. Logan, M.T. Paffett, Steady-State co Oxidation Kinetics Over the Pd(100) Single Crystal Surface and the c(2 $\times 2)$ Sn/Pd(100) Bimetallic Surface Alloy, J. Catal., 133 (1992) 179-190.

[9] H.S. Gandhi, G.W. Graham, R.W. McCabe, Automotive Exhaust Catalysis, J. Catal., 216 (2003) 433-442.

[10] C.D. Zeinalipour-Yazdi, A.M. Efstathiou, Preadsorbed Water-Promoted Mechanism of the Water-Gas Shift Reaction, J. Phys. Chem. C, 112 (2008) 19030-19039.

[11] N.P. Lebedeva, M.T.M. Koper, E. Herrero, J.M. Feliu, R.A. van Santen, CO oxidation on stepped Pt $[\mathrm{n}(111) \mathrm{x}(111)]$ electrodes, J. Electroanal. Chem., 487 (2000) 37-44.

[12] A.C. Lausche, A.J. Medford, T.S. Khan, Y. Xu, T. Bligaard, F. Abild-Pedersen, J.K. Nørskov, F. Studt, On the effect of coverage-dependent adsorbate-adsorbate interactions for CO methanation on transition metal surfaces, J. Catal., 307 (2013) 275-282.

[13] S. Shan, V. Petkov, L. Yang, J. Luo, P. Joseph, D. Mayzel, B. Prasai, L. Wang, M. Engelhard, C.J. Zhong, Atomicstructural synergy for catalytic CO oxidation over palladium-nickel nanoalloys, Journal of the American Chemical Society, 136 (2014) 7140-7151.

[14] A.F. Lee, C.V. Ellis, K. Wilson, N.S. Hondow, In situ studies of titania-supported Au shell-Pd core nanoparticles for the selective aerobic oxidation of crotyl alcohol, Catal. Today, 157 (2010) 243-249.

[15] C.M.A. Parlett, D.W. Bruce, N.S. Hondow, M.A. Newton, A.F. Lee, K. Wilson, Mesoporous Silicas as Versatile Supports to Tune the Palladium-Catalyzed Selective Aerobic Oxidation of Allylic Alcohols, ChemCatChem, 5 (2013) 939950.

[16] C.D. Zeinalipour-Yazdi, R.A. van Santen, Coverage-Dependent Adsorption Energy Trends of CO on a Rhodium Nanocluster, J. Phys. Chem. C, 116 (2012) 8721-8730.

[17] C.D. Zeinalipour-Yazdi, A.L. Cooksy, A.M. Efstathiou, CO Adsorption on Transition Metal Clusters: Trends from Density Functional Theory, Surf. Sci., 602 (2008) 1858-1862. 
[18] C.D. Zeinalipour-Yazdi, A.L. Cooksy, A.M. Efstathiou, A Diffuse Reflectance Infrared Fourier-Transform Spectra and Density Functional Theory Study of CO Adsorption on Rh/ $\gamma-\mathrm{Al}_{2} \mathrm{O}_{3}$, J. Phys. Chem. C, 111 (2007) 13872-13878.

[19] K.A. Kacprzak, I. Czekaj, J. Mantzaras, DFT Studies of Oxidation Routes for Pd ${ }_{9}$ Clusters Supported on $\gamma$-Alumina, Phys. Chem. Chem. Phys., 14 (2012) 10243-10247.

[20] Z.-P. Liu, S.J. Jenkins, D.A. King, Origin and Activity of Oxidized Gold in Water-Gas-Shift Catalysis, Phys. Rev. Lett., $94(2005) 196102$.

[21] L.M. Molina, B. Hammer, Theoretical study of CO oxidation on Au nanoparticles supported by $\mathrm{MgO}(100) \ldots$, Phys. Rev. B, 69 (2004) 155424.

[22] D.A.J.M. Ligthart, R.A. van Santen, E.J.M. Hensen, Supported rhodium oxide nanoparticles as highly active CO oxidation catalysts, Ang. Chem. - Int. Ed., 50 (2011) 5306-5310.

[23] I.V. Yudanov, R. Sahnoun, K.M. Neyman, N. Rösch, J. Hoffmann, S. Schauermann, V. Johánek, H. Unterhalt, G. Rupprechter, J. Libuda, H.-J. Freund, CO Adsorption on Pd Nanoparticles: Density Functional and Vibrational Spectroscopy Studies, J. Phys. Chem. B, 107 (2003) 255-264.

[24] H. Unterhalt, G. Rupprechter, H.-J. Freund, Vibrational Sum Frequency Spectroscopy on Pd(111) and Supported Pd Nanoparticles: CO Adsorption from Ultrahigh Vacuum to Atmospheric Pressure, J. Phys. Chem. B, 106 (6) 356-367.

[25] G. Rupprechter, H. Unterhalt, M. Morkel, P. Galletto, L. Hu, H.-J. Freund, Sum Frequency Generation Vibrational Spectroscopy at Solid-Gas Interfaces: CO Adsorption on Pd Model Catalysts at Ambient Pressure, Surf. Sci., $502-503$ (2002) 109-122.

[26] T. Dellwig, G. Rupprechter, H. Unterhalt, H.-J. Freund, Bridging the Pressure and Materials Gaps: High Pressure Sum Frequency Generation Study on Supported Pd Nanoparticles, Phys. Rev. Lett., 85 (2000) 776.

[27] V. Fernandez, T. Giessel, O. Schaff, K.M. Schindler, A. Theobald, C.J. Hirschmugl, S. Bao, A.M. Bradshaw, C. Baddeley, A.F. Lee, R.M. Lambert, D.P. Woodruff, V. Fritzsche, A photoelectron diffraction study of the $\operatorname{Pd}\{111\}$ (root $3 x$ root 3)R30 degrees-CO chemisorption phase, Z. Phys. Chemie-Int. J. Res. Phys. Chem. Chem. Phys., 198 (1997) 73-85.

[28] M. Tüshaus, W. Berndt, H. Conrad, A.M. Bradshaw, B. Persson, Understanding the structure of high coverage CO adlayers, Appl. Phys. A, 51 (1990) 91-98.

[29] J. Szanyi, D.W. Goodman, CO Oxidation on Palladium. 1. A Combined Kinetic-Infrared Reflection Absorption Spectroscopic Study of Pd(100), J. Phys. Chem., 98 (1994) 2972-2977.

[30] H. Dropsch, M. Baerns, CO Adsorption on Supported Pd Catalysts Studied by Adsorption Microcalorimetry and TPD, Appl. Catal. A: Gen., 158 (1997) 163-183.

[31] J.M. Flores-Camacho, J.-H. Fischer-Wolfarth, M. Peter, C.T. Campell, S. Shauermann, H.-J. Freund, Adsorption Energetics of CO on Supported Pd Nanoparticles as a Function of Particle size by Single Crystal Microcalorimetry, Phys. Chem. Chem. Phys., 13 (2011) 16800-16810.

[32] J.-H. Fischer-Wolfarth, J.A. Farmer, J.M. Flores-Camacho, A. Genest, I.V. Yudanov, N. Rösch, C.T. Campbell, S. Schauermann, H.-J. Freund, Particle-size dependent heats of adsorption of CO on supported Pd nanoparticles as measured with a single-crystal microcalorimeter, Phys. Rev. B, 81 (2010).

[33] P.J. Feibelman, B. Hammer, J.K. Nørskov, F. Wagner, M. Scheffler, R. Stumpf, R. Watwe, J. Dumesic, The CO/Pt(111) Puzzle, J. Phys. Chem. B, 105 (2001) 4018.

[34] B. Hammer, Y. Morikawa, J.K. Nørskov, CO Chemisorption at Metal Surfaces and Overlayers, Physical Review Letters, 76 (1996) 2141-2144.

[35] V. Bertin, E. Agacino, R. López-Rendon, E. Poulain, The CO Chemisorption on Some Active Sites of Pd Clusters: A DFT Study, J. Molec. Struct.: THEOCHEM, 796 (2006) 243-248.

[36] P. Sautet, M.K. Rose, J.C. Dunphy, S. Behler, M. Salmeron, Adsorption and energetics of isolated CO molecules on Pd(111), Surface Science, 453 (2000) 25-31.

[37] J.A. Herron, S. Tonelli, M. Mavrikakis, Atomic and molecular adsorption on Pd(111), Surface Science, 606 (2012) $1670-1679$.

[38] M.K. Rose, T. Mitsui, J. Dunphy, A. Borg, D.F. Ogletree, M. Salmeron, P. Sautet, Ordered structures of CO on Pd(111) studied by STM, Surface Science, 512 (2002) 48-60.

[39] M. Morkel, H. Unterhalt, T. Klüner, G. Rupprechter, H.-J. Freund, Interpreting Intensities in Vibrational Sum Frequency Generation (SFG) Spectroscopy: CO Adsorption on Pd Surfaces, Surf. Sci., 586 (2005) 146-156.

[40] I.V. Yudanov, M. Metzner, A. Genest, N. Rösch, Size-Dependence of Adsorption Properties of Metal Nanoparticles: a DFT study on Palladium Nanoclusters, J. Phys. Chem. C, 112 (2008) 20269-20275.

[41] I.V. Yudanov, A. Genest, S. Schauermann, H.-J. Freund, N. Rösch, Size Dependence of the Adsorption Energy of CO on Metal Nanoparticles: a DFT Search for the Minimum Value, Nano letters, 12 (2012) 2134-2139.

[42] B. Zhu, G. Thrimurthulu, L. Delannoy, C. Louis, C. Mottet, J. Creuze, B. Legrand, H. Guesmi, Evidence of Pd Segregation and Stabilization at Edges of AuPd Nano-Clusters in the Presence of CO: A Combined DFT and DRIFTS Study, J. Catal., 308 (2013) 272-281.

[43] R.C. Gaussian 09, M. J. Frisch, G. W. Trucks, H. B. Schlegel, G. E., M.A.R. Scuseria, J. R. Cheeseman, G. Scalmani, V. Barone, B. Mennucci,, M.C. G. A. Petersson, in, Gaussian Inc., Wallingford CT, 2009. 
[44] A.D. Becke, Density-Functional Thermochemistry. III. The Role of Exact Exchange, J. Chem. Phys., 98 (1993) 5648.

[45] C. Lee, W. Yang, R.G. Parr, Development of the Colle-Salvetti Correlation-Energy Formula into a Functional of the Electron Density, Phys. Rev. B, 37 (1988) 785.

[46] Y. Zhao, D.G. Truhlar, The M06 Suite of Density Functionals for Main Group Thermochemistry, Thermochemical Kinetics, Noncovalent Interactions, Excited States, and Transition Elements: Two New Functionals and Systematic Testing of four M06-Class Functionals and 12 Other Functionals, Theor. Chem. Acc., 120 (2008) 215-241.

[47] J.M. Tao, J.P. Perdew, V.N. Staroverov, G.E. Scuseria, Climbing the Density Functional Ladder: Nonempirical MetaGeneralized Gradient Approximation Designed for Molecules and Solids,, Phys. Rev. Lett., 91 (2003) 146401.

[48] O.A. Vydrov, G.E. Scuseria, J.P. Perdew, Tests of Functionals for Systems with Fractional Electron Number, J. Chem. Phys., 126 (2007) 154109.

[49] J.P. Perdew, K. Burke, M. Ernzerhof, Generalized Gradient Approximation Made Simple, Phys. Rev. Lett., 77 (1996) 3865-3868.

[50] C. Adamo, V. Barone, Exchange Functionals With Improved Long-Range Behavior and Adiabatic Connection Methods Without Adjustable Parameters: The mPW and mPW1PW Models, J. Chem. Phys., 108 (1998) 664-675.

[51] W.J. Hehre, R.F. Stewart, J.A. Pople, Self-Consistent Molecular Orbital Methods. 1. Use of Gaussian expansions of Slater-Type Atomic Orbitals, J. Chem. Phys., 51 (1969) 2657-2664.

[52] W.R. Wadt, P.J. Hay, Ab Initio Effective Core Potentials for Molecular Calculations - Potentials for Main Group Elements Na to Bi, J. Chem. Phys., 82 (1985 ) 284-298.

[53] T.H. Dunning Jr., P.J. Hay, Modern Theoretical Chemistry, Plenum, New York, 1976.

[54] W.J. Stevens, H. Basch, M. Krauss, Compact Effective Potentials and Efficient Shared-Exponent Basis-Sets for the 1stRow and 2nd-Row Atoms, J. Chem. Phys., 81 (1984) 6026-6033.

[55] W.J. Stevens, M. Krauss, H. Basch, P.G. Jasien, Relativistic Compact Effective Potentials and Efficient, SharedExponent Basis Sets for The Third-, Fourth-, and Fifth-Row Atoms, Can. J. Chem., 70 (1992) 612-630.

[56] D.E. Woon, T.H. Dunning Jr., Gaussian Basis Sets for Use in Correlated Molecular Calculations. III. The Atoms Aluminum Through Argon J. Chem. Phys., 98 (1993) 1358.

[57] A. Wilson, T. van Mourik, T.H. Dunning Jr., Gaussian Basis Sets for Use in Correlated Molecular Calculations. VI. Sextuple Zeta Correlation Consistent Basis Sets for Boron Through Neon, J. Mol. Struct., 388 (1997) 339-349.

[58] K.A. Peterson, D.E. Woon, T.H. Dunning Jr., Benchmark Calculations with Correlated Molecular Wave Functions. IV. The Classical Barrier Height of the $\mathrm{H}+\mathrm{H}_{2} \rightarrow \mathrm{H}_{2}+\mathrm{H}$ Reaction, J. Chem. Phys., 100 (1994) 7410.

[59] R.A. Kendall, T.H. Dunning Jr., R.J. Harrison, Electron Affinities of the First-Row Atoms Revisited. Systematic Basis Sets and Wave Functions J. Chem. Phys., 96 (1992) 6796.

[60] T.H. Dunning Jr., Gaussian Basis Sets for use in Correlated Molecular Calculations. I. The Atoms Boron Through Neon and Hydrogen J. Chem. Phys., 90 (1989) 1007.

[61] F. Weigend, F. Furche, R. Ahlrichs, Gaussian Basis Sets of Quadruple Zeta Valence Quality for Atoms H-Kr, J. Chem. Phys., 119 (2003) 12753.

[62] F. Weigend, R. Ahlrichs, Balanced Basis Sets of Split Valence, Triple Zeta Valence andQuadruple Zeta Valence Quality for H to Rn: Design and Assessment of Accuracy, Phys. Chem. Chem. Phys., 7 (2005) 3297-3305.

[63] S.F. Boys, F. Bernardi, The Calculation of Small Molecular Interactions by the Differences of Separate Total Energies. Some Procedures With Reduced Errors, Mol. Phys., 19 (1970) 553-566.

[64] I.V. Yudanov, M. Metzner, A. Genest, N. Rösch, Size-dependence of adsorption properties of metal nanoparticles_a DFT study on palladium nanoclusters, J. Phys. Chem. C, 112 (2008) 20269-20275.

[65] H.J. Monkhorst, J.D. Pack, SPECIAL POINTS FOR BRILLOUIN-ZONE INTEGRATIONS, Phys. Rev. B, 13 (1976) $5188-5192$.

[66] G. Kresse, J. Furthmüller, Efficient iterative schemes for ab initio total-energy calculations using a plane-wave basis set, Phys. Rev. B, 54 (1996) 11169-11186.

[67] G. Kresse, J. Hafner, ABINITIO MOLECULAR-DYNAMICS FOR LIQUID-METALS, Phys. Rev. B, 47 (1993) 558-561.

[68] J.P. Perdew, K. Burke, M. Ernzerhof, Generalized Gradient Approximation Made Simple Phys. Rev. Lett. , 77 (1996) $3865-3868$.

[69] G. Kresse, D. Jouber, From Ultrasoft Pseudopotentials to the Projector Augmented-Wave Method, Phys Rev. B, 59 (1999) 1758.

[70] P.E. Blöchl, Projector Augmented-Wave Method, Phys. Rev. B, 50 (1994) 17953.

[71] J. Paier, M. Marsman, G. Kresse, Why does the B3LYP hybrid functional fail for metals?, The Journal of chemical physics, 127 (2007) 024103.

[72] K. Mogi, Y. Sakai, T. Sonoda, Q. Xu, Y. Souma, Geometries and Electronic Structures of Group 10 and 11 Metal Carbonyl Cations, $[\mathrm{M}(\mathrm{CO}) \mathrm{n}] \mathrm{x}+\left(\mathrm{Mx}+=\mathrm{Ni2}+, \mathrm{Pd} 2+, \mathrm{Pt} 2+, \mathrm{Cu}+, \mathrm{Ag}^{+}, \mathrm{Au}+; \mathrm{n}=1-4\right)$, The Journal of Physical Chemistry A, 107 (2003) 3812-3821.

[73] P.C. Gravelle, Heat-Flow Microcalorimetry and Its Application to Heterogeneous Catalysis, Adv. Catal., 22 (1972) 191. 
[74] P.C. Gravelle, CALORIMETRY IN ADSORPTION AND HETEROGENEOUS CATALYSIS STUDIES, Catal. Rev. Sci. Eng., 16 (1977) 37.

[75] G. Zanti, D. Peeters, DFT Study of Small Palladium Clusters Pdnand Their Interaction with a CO Ligand (n=1-9), Eur. J. Inorg. Chem., (2009) 3904-3911.

[76] D. Dai, K. Balasubramanian, ELECTRONIC-STRUCTURES OF PD-4 AND PT-4 J. Chem. Phys., 103 (1995) 648655.

[77] G. Blyholder, Molecular orbital view of chemisorbed carbon monoxide, J. Phys. Chem., 68 (1964) 2772-2777.

[78] P. Gruene, A. Fielicke, G. Meijer, D.M. Rayner, The adsorption of CO on group 10 (Ni, Pd, Pt) transition-metal clusters, Physical Chemistry Chemical Physics, 10 (2008) 6144-6149.

[79] T. Komeda, Y. Kim, M. Kawai, Lateral Motion of Adsorbate Induced by Vibrational Mode Excitation With Inelastic Tunneling Electron, Surf. Sci., 502-503 (2002) 12-17.

[80] K.L. Wong, B.V. Rao, G. Pawin, E. Ulin-Avila, L. Bartels, Coverage and Nearest-Neighbor Dependence of Adsorbate Diffusion, J. Chem. Phys., 123 (2005) 201102.

[81] M. Peter, S. Adamovsky, J.M. Flores Camacho, S. Schauermann, Energetics of Elementary Reaction Steps Relevant for CO Oxidation: $\mathrm{CO}$ and $\mathrm{O}_{2}$ Adsorption on Model Pd Nanoparticles and Pd(111), Faraday Discuss., 162 (2013) 341-354.

[82] H. Unterhalt, G. Rupprechter, H.-J. Freund, Vibrational Sum Frequency Spectroscopy on Pd(111) and Supported Pd Nanoparticles: CO Adsorption from Ultrahigh Vacuum to Atmospheric Pressure, J. Phys. Chem. B, 106 (2001) 356-367.

[83] S. Bertarione, D. Scarano, A. Zecchina, V. Johánek, J. Hoffmann, S. Schauermann, M.M. Frank, J. Libuda, G. Rupprechter, H.-J. Freund, Surface Reactivity of Pd Nanoparticles Supported on Polycrystalline Substrates As Compared to Thin Film Model Catalysts: Infrared Study of CO Adsorption, J. Phys. Chem. B, 108 (2004) 3603-3613.

[84] T. Lear, R. Marshall, E.K. Gibson, T. Schutt, T.M. Klapotke, G. Rupprechter, H.-J. Freund, J.M. Winfield, D. Lennon, A Model High Surface Area Alumina-Supported Palladium Catalyst, Phys. Chem. Chem. Phys., 7 (2005) 565-567.

[85] M. Scheffler, The Influence of Lateral Interactions on the Vibrational Spectrum of Adsorbed CO, Surf. Sci., 81 (1979) 562-570.

[86] K. Wolter, O. Seiferth, H. Kuhlenbeck, M. Baumer, H.-J. Freund, Infrared Spectroscopic Investigation of CO Adsorbed on Pd Aggregates Deposited on Alumina Model Support, Surf. Sci., 399 (1998) 190-198.

[87] W.K. Kuhn, J. Szanyi, D.W. Goodman, CO Adsorption on Pd(111): the Effects of Temperature anf Pressure, Surf. Sci. Lett., 274 (1992) L611-L618.

[88] S. Zou, I. Villegas, C. Stuhlmann, M.J. Weaver, Nanoscale Phenomena in Surface Electrochemistry: Some Insights from Scanning Tunneling Microscopy and Infrared Spectroscopy, Electrochim. Acta, 43 (1998) 2811-2824.

[89] P.S. Bagus, C.J. Nelin, C.W. Bauschlicher, BONDING OF CO TO METAL-SURFACES - A NEW INTERPRETATION, Physical Review B, 28 (1983) 5423-5438.

[90] T.O. Menteş, N. Stojić, N. Binggeli, M.A. Niño, A. Locatelli, L. Aballe, M. Kiskinova, E. Bauer, Strain Relaxation in Small Adsorbate Islands: O on W(110), Phys. Rev. B, 77 (2008) 155414.

[91] V. Kumar, Y. Kawazoe, Icosahedral Growth, Magnetic Behavior, and Adsorbate-Induced Metal-Nonmetal Transition in Palladium Clusters, Phys. Rev. B, 66 (2002) 144413.

[92] M. Mavrikakis, B. Hammer, J.K. Nørskov, Effect of Strain on the Reactivity of Metal Surfaces, Phys. Rev. Lett., 81 (1998) 2819-2822.

Table of Content - Graphic

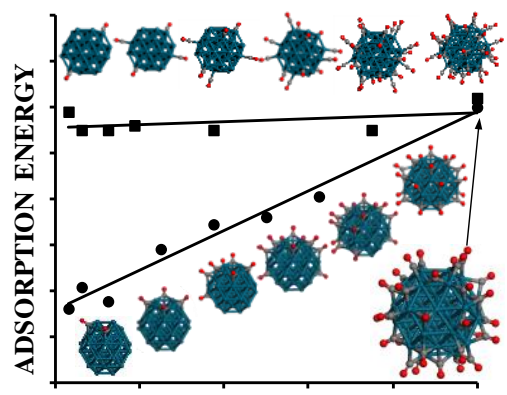

COVERAGE 